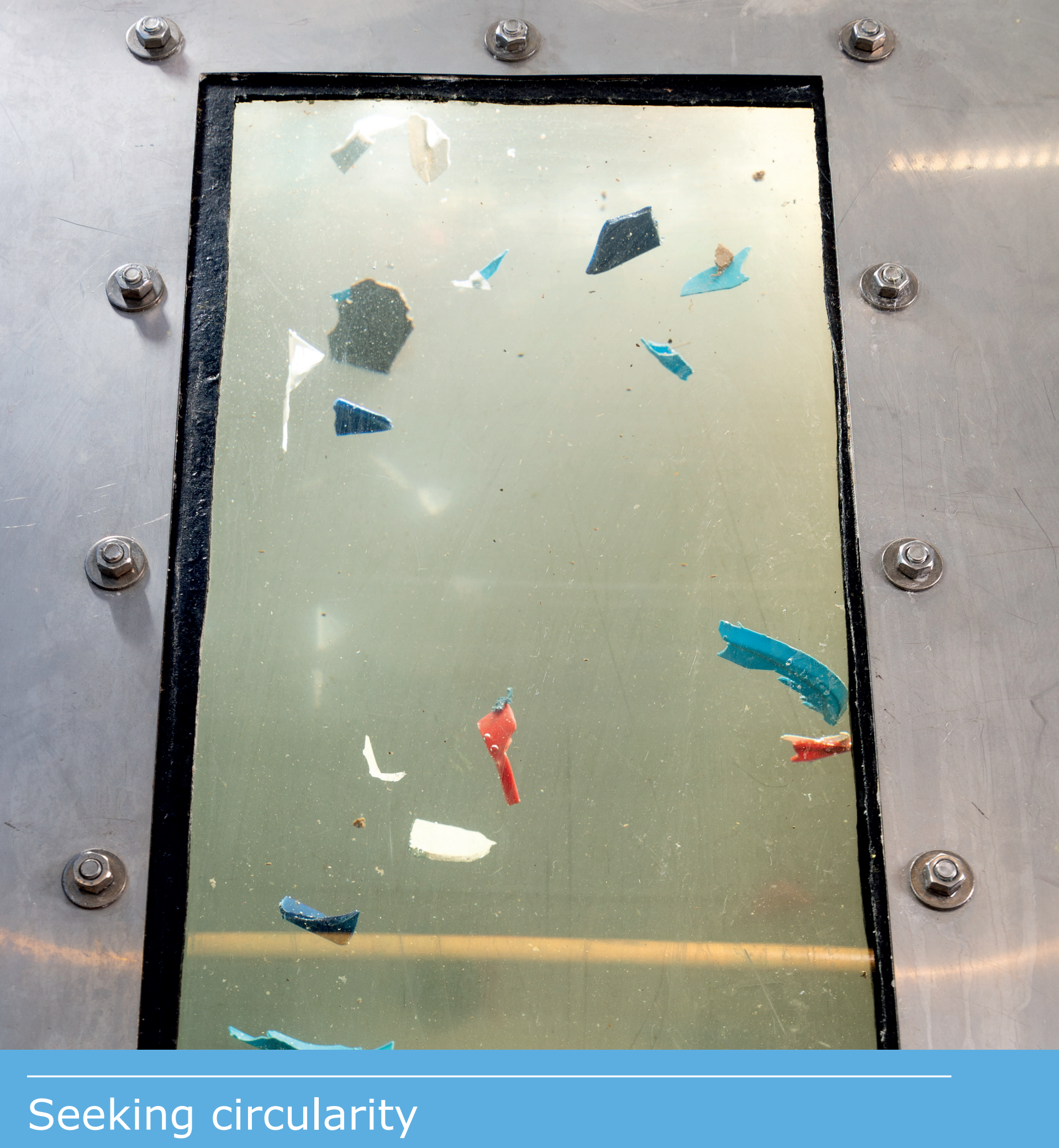

Finding sustainable packaging solutions for fresh products

E.U. Thoden van Velzen

WAGENINGEN

UNIVERSITY \& RESEARCH 



\section{Seeking circularity}

Finding sustainable packaging solutions for fresh products

Author: E.U. Thoden van Velzen

This research project has been carried out by Wageningen Food \& Biobased Research, in the context of DFI-AF-19003 (project number 6239192301). 
Version: final

Reviewer: Fatima Pereira da Silva

Approved by: Arie van der Bent

Sponsor: DFI Top sector

This report can be downloaded for free at https://doi.org/10.18174/526932 or at www.wur.eu/wfbr (under publications).

(C) 2020 Wageningen Food \& Biobased Research, institute within the legal entity Stichting Wageningen Research.

The client is entitled to disclose this report in full and make it available to third parties for review. Without prior written consent from Wageningen Food \& Biobased Research, it is not permitted to:

a. partially publish this report created by Wageningen Food \& Biobased Research or partially disclose it in any other way;

b. (let a third party) use this report created by Wageningen Food \& Biobased Research or the name of the report or Wageningen Food \& Biobased Research in whole or in part for the purposes of making claims, conducting legal procedures, for (negative) publicity, and for recruitment in a more general sense;

c. use the name of Wageningen Food \& Biobased Research in a different sense than as the author of this report.

PO box 17, 6700 AA Wageningen, The Netherlands, T + 31 (0)317 4800 84, E info.wfbr@wur.nl, www.wur.eu/wfbr. Wageningen Food \& Biobased Research is part of Wageningen University \& Research.

All rights reserved. No part of this publication may be reproduced, stored in a retrieval system of any nature, or transmitted, in any form or by any means, electronic, mechanical, photocopying, recording or otherwise, without the prior permission of the publisher. The publisher does not accept any liability for inaccuracies in this report. 


\section{Contents}

$\begin{array}{ll}\text { Summary } & 4\end{array}$

$\begin{array}{lr}\text { Samenvatting } & 5\end{array}$

1 Introduction $\quad 6$

$\begin{array}{llr}1.1 & \text { Plastic packages in multiple perspectives } & 6\end{array}$

1.2 Objectives $\quad 8$

$\begin{array}{lll}1.3 & \text { Project information } & 9\end{array}$

$\begin{array}{llr}1.4 & \text { Definitions } & 9\end{array}$

2 Methods $r 11$

2.1 Interviews 11

$\begin{array}{ll}2.2 & \text { Analysis of the packages } \\ \end{array}$

2.3 Packaging assessment 11

2.3.1 Plastic usage $\quad 12$

2.3.2 Environmental impact of the food-packaging systems $\quad 12$

$\begin{array}{ll}\text { 2.3.3 Business costs for the packaging industry } & 13\end{array}$

2.3.4 Business costs for the retail organisation 13

$\begin{array}{lll}2.3 .5 & \text { Recyclability indicators } & 13\end{array}$

$\begin{array}{ll}\text { 2.3.6 Littering prevention indicator } & 13\end{array}$

$3 \quad$ Fruit and vegetables $r$

$\begin{array}{llr}3.1 & \text { Overview of opportunities } & 15\end{array}$

$\begin{array}{ll}3.2 \text { Snack tomatoes } & 16\end{array}$

3.2.1 Performance indicators $\quad 16$

$\begin{array}{ll}3.2 .2 & \text { Reflection on snack tomatoes }\end{array}$

$4 \quad$ Poultry meat products $\quad 23$

5 Discussion $\quad 29$

5.1 Can we live without plastic packaging in a modern society?

5.2 Sustainable packages, food industries in the lead $\quad 29$

$\begin{array}{lll}5.3 & \text { Informed decisions need reliable data } & 31\end{array}$

5.4 There is no single answer to all environmental concerns 32

$\begin{array}{llr}6 & \text { Conclusions } & 33\end{array}$

$\begin{array}{ll}\text { Literature } & 34\end{array}$

$\begin{array}{lr}\text { Abbreviations } & 37\end{array}$

$\begin{array}{lll}\text { Annex } 1 & \text { Research data } & 38\end{array}$

$\begin{array}{lll}\text { Annex } 2 & \text { Interviewed incumbents } & 41\end{array}$

Annex $3 \quad$ Sensitivity analysis $\quad 42$

Annex 4 Qualitative substantiation of the business costs 43 


\section{Summary}

This study explores the options to make fresh food packages more sustainable, recyclable or even circular recyclable. The packaging options for two fresh food products were examined: snack tomatoes and poultry meat products. The study revealed that there are indeed possibilities to make these packages recyclable and limit the environmental impact of the product-packaging combination. None of the currently available packages is circular recyclable and neither will they not potentially contribute to the formation of litter. However, existing packaging options can become circular recyclable in the near future when the required recycling technologies are developed. The quest for more circular recyclable packages did reveal several dilemmas. These dilemmas concern the whole value chains of both the product and the package and cannot be resolved by the food company alone. The quarry for more circular recyclable packages can only succeed when all the stakeholders are involved, including the citizens.

Food companies can pursue multiple sustainability strategies (limit food waste, limit environmental impacts of the food-packaging combination, recyclability, circularity, limit the impact of littered packages) and all these strategies will render different packaging designs. 


\section{Samenvatting}

In deze studie is onderzocht wat de mogelijkheden zijn om verpakkingen voor verse levensmiddelen te verduurzamen en hen recyclebaar of zelfs circulair recyclebaar te maken. Deze verkenning is uitgevoerd voor twee verse levensmiddelen: snoeptomaten en kippenvlees. Hieruit blijkt dat er mogelijkheden zijn om de verpakkingen recyclebaar te maken en ook om de milieueffecten van de totale levensmiddel-product-combinatie te beperken. Geen enkele verpakking is echter circulair recyclebaar en ook zal geen enkele verpakking in potentie niet bijdragen aan de vorming van zwerfafval. Wel kunnen in de toekomst bestaande verpakkingsvormen circulair recyclebaar worden als de benodigde recyclingtechnologie wordt ontwikkeld. Bij het streven naar meer circulair recyclebare verpakkingen kwamen meerdere dilemma's aan het licht. Enkele van die dilemma's blijken heel algemeen van aard en kunnen ook niet door alleen het verpakkende bedrijf worden opgelost. Het streven naar circulariteit kan alleen welslagen met de betrokkenheid van alle belanghebbenden, inclusief de burgers.

Verpakkende bedrijven kunnen meerdere verduurzamingsstrategieën nastreven (beperken voedselverspilling, verlaging totale milieudruk product-verpakkingssysteem, recyclebaar maken verpakkingen, circulair maken verpakkingen, beperken negatieve gevolgen van zwerfafval) en al deze strategieën leveren andere verpakkingsontwerpen op. 


\section{Introduction}

\subsection{Plastic packages in multiple perspectives}

The food distribution system in Europe gradually developed during the post-war years to a complex system with tens of thousands perishable products in protective packages. The lion's share of these perishable products are protected by plastic packages. These plastic packages have been developed over decades to have the highest performance with the lowest packaging weight, due to cost and eco-efficiency considerations. This resulted in a great number of plastic packaging types, including so-called multi-layered flexible performance materials.

In the nineties the European Union started to demand that member states would recycle their packaging waste [EU 64/92]. This was relatively easily implemented for paper \& board, metal and glass packages. This proved to be much more challenging for plastic packages, since these packages were optimised for their packaging performance and generally not designed for recycling. Initial postconsumer plastic packaging recycling schemes therefore targeted the relatively easy to recycle bottles. The number of member states involved in the separate collection and recycling of post-consumer plastic packaging waste grew steadily over the years, as did the portfolio of packages that was targeted for recycling. The non-recyclability of the plastic packages became an increasing issue for recycling facilities and extended producer responsibility (EPR) schemes.

With the discovery of plastic soup in the oceans in 2007, the public opinion started to shift [Teuten et al. 2009; Lebreton et al. 2018]. Gradually the magnitude of the problem and the causes became apparent. The lack of waste management infrastructure in many developing countries implied that much of the plastic packaging flushes with the rainfall into the oceans. On top of that, many developed countries used to send their mixed plastic packaging waste in containers to Asia, to be recycled. This was registered as recycled and hence helped the sending country to achieve its recycling target. In the receiving countries the relatively valuable articles were manually sorted out of this mix and the rest was either landfilled, dumped in rivers or burned in open air fires. All in all, these so-called recycling activities caused more plastic waste to enter the oceans and additional air pollution. When the public awareness grew in Western-Europe that also their system to use and discard plastic packages contributed to marine litter, the Ellen MacArthur Foundation released its vision for a new plastic economy in 2016 [Ellen MacArthur Foundation, 2016]. A vision in which the leakage of plastics to the environment is stopped, an effective after market for plastic waste is created and the plastic industry is decoupled from fossil feedstock. Although well-received, the technologies for achieving this grand transition lacked. Furthermore, also a clear transition pathway to achieve this New Plastic Economy was absent, which is critical since the transition contains a few apparently contradictory elements. For instance, how to decouple from fossil feedstock and simultaneously establish a sorting and recycling infrastructure? As the latter currently still relies on fossil-based packages, this will automatically create a lock-in and retard the market adaptation of bio-based packages that are not made from drop in materials [Crippa et al., 2019]. Secondly, how to avoid the leakage of plastics to the environment with EPR schemes in which civilians are responsible to discard their plastic waste correctly [Crippa et al., 2019]? Thirdly, how can the material use per package be reduced and the level of recyclability of these packages be maintained?

In the meantime, multiple European research groups analysed the plastic packaging recycling systems in their country, from which it became evident that these collection and recycling systems are fairly inefficient [van Eygen et al., 2017; Dahlbo et al., 2018; Brouwer et al., 2018; Hahladakis et al., 2018]. It was found that these systems have low recycling rates and predominantly render recycled plastics of low qualities. Consequently a growing group of stakeholders became convinced that these collection and recycling systems, when left unaltered, will not enable the desired new plastic economy.

In the meantime the public awareness about plastic soup in the oceans grew. Especially in western Europe this resulted in public discontent about plastic in general, the rise and fall of 'plastic free' shops, etc. Pressure groups such as Green Peace, Plastic Soup Foundation, WWF, etc. demanded politicians, brand-owners and retailers to stop using plastics. Simultaneously, civilians admitted that they are unlikely to change their habits and/or support political measures to alleviate the issue [Ipsos Mori 2018]. 
As a response to the growing discontent with plastics and littering, the EU council announced its plastic strategy in 2018 [EU 2018]. This new strategy aims to abolish single-use plastics (SUP), reduce the use of plastic packages and set up a circular economy for plastic packages. Subsequently, the single use plastic directive was released [EU 2019/904]. Initially the proposal text was interpreted that all plastic packages for ready-to-eat food products would be considered as a SUP and hence would be forbidden. This fuelled confusion and disbelief with food industries. Later the exemption was introduced in the SUP directive for plastic packages that are a part of an EPR scheme.

Nevertheless, amidst this confusion retail organisations and food packaging companies were urged to reconsider their plastic packages and explore options to abolish, reduce and replace their usage of plastic packages and make them fit better in a circular economy. However, these incumbents soon realised that most alternative solutions have specific drawbacks. For instance, the complete abolishment of plastic packages would result in much more foods being wasted, which would generate a large negative environmental impact. Hence the potential impacts of such a measure should be always carefully assessed in advance [White \& Lockyer 2020]. Alternatively a shift from plastic packages to paper \& board based packages can also result in higher emissions of greenhouse gases [Abejón et al., 2020; Green Alliance, 2020] and could potentially create new food safety concerns that have to be assessed and managed [Pivnenko et al. 2015; Koster et al. 2020]. As a result, many food companies are looking for scientific guidance in their attempts to progress towards circularity for their packaged products.

In response to the growing societal pressure to reduce the use of plastic packages, the management of several large food companies and retail organisations stated that their packages will either be recyclable, reusable or compostable by either 2025 or 2030 . This added to the pressure to find solutions to make food packages more circular for the packaging designers and technologists working in food companies. In the Netherlands, many producers of packed food products undersigned the Plastic Pact and promised to reduce the amount of packaging materials with $20 \%$, to use only reusable, recyclable, or compostable ${ }^{1}$ packaging materials by 2025 , and to apply $35 \%$ of recycled content in the food packages [Plastic Pact, 2019]. Simultaneously, multinationals made similar statements, which were listed in a progress report [Ellen MacArthur Foundation, 2019].

In February 2020 the Covid-19 pandemic arrived in Europe. All businesses were affected. It boosted the retail sales of fresh food products greatly, critically testing the food supply chains. Several representatives of retail outlets noticed that the sales of pre-packed vegetables grew in these months. Furthermore, a few consumers asked for more hygienic measures and to re-pack products such as egg-plant and courgette. Although the Covid-19 crises readdressed the hygienic function of plastic packages for fresh foods, it did not result in a complete mind-shift with packaging designers and technologists.

The intentions of food companies and retail organisations with respect to packaging, are still to strive towards a circular economy for plastic packages and to show to the consumer that they are addressing the issues with plastic packaging in a serious manner. The most common strategies that are being employed and tested to reach these goals are:

- $\quad$ Rethink. The complete redesign of the product-packaging-system, by which the packaging becomes obsolete,

- $\quad$ Reduce. Reduce the amount of packaging material, or in some cases the amount of plastic packaging material per amount of packaged product,

- $\quad$ Reuse. Introduce reusable packages and filling stations in outlets. Or to give discounts for clients that bring their own coffee mug or package for instance.

- Replace. To replace plastic materials with alternative materials such as: paper \& board, glass, metal, bio-based plastics and biodegradable plastics.

- Redesign. To change the composition of the material in such a manner that the package becomes recyclable.

\footnotetext{
${ }^{1}$ A reusable package is package that can be used in multiple loops, such as plastic crates in a pool. A recyclable package is a package of which the material can be retrieved and reused (see section 1.4) and a compostable package is package that is broken down by micro-biological degradation in a industrial composting facility according to EN 13432.
} 
These strategies often result in dilemmas, since they generally do not simultaneously result in improvements with respect to environmental impacts, the perceived environmental impact, the littering impact, food safety and sales. Furthermore, several strategies have resulted in strong opposition of other stakeholders (retailers, waste management companies). These dilemmas and responses hinder the progress towards a more sustainable and circular plastic packaging recycling system.

\section{Scientific challenges}

There are multiple scientific challenges in relation to the quest for more circular recyclable food packages.

On a fundamental level, the guiding principles of an ideal circular economy have been refuted with thermodynamic and economic considerations [Skene, 2018]. The ideal of a complete circular economy is an unrealistic utopia. The influx of substantial amounts of energy are required to progress towards a more circular economy. Any practical circular economy will rely on the inflow of new materials and the outflow of contaminated materials. Therefore, for every material the practically achievable balance has to be found between the amount of material that remains in circulation and the required efforts for maintaining this recirculation, without compromising the quality and safety of the material. Which level is acceptable for a population is therefore a political and not a scientific question.

On a practical level, not all environmental impacts can be calculated with the same level of accuracy, complicating any overview or comparison of impacts. The environmental sciences have progressed largely over the last half a century, resulting in reliable calculation methods for several important impact categories. But in case crucial information is unknown, as is often the case with for instance the food loss rates of individual packaging types, the calculation of environmental impacts is only an approximation. Finally, there are several forms of impact for which an widely accepted calculation method is lacking; littering, plastic soup. These impacts are in the focus of the societal attention, but there are no methods to quantify the contribution of individual packages to these kind of impacts in a reliable manner.

\subsection{Objectives}

This report aims to assess the options that food packaging industries have to make their current food packages more circular by replacing them for more sustainable options. Furthermore, it aims to describe the dilemmas that these companies experience with those more sustainable alternatives. This will hopefully result in increased awareness and subsequently in systemic changes to enable further progress.

To explore those dilemmas, these more sustainable packaging options are assessed and compared with respect to the following criteria:

- Plastic use per amount of packaged product,

- Expected packaging related food losses, including exceedance of the best-before-date,

- Estimated greenhouse gas emissions of the production, use and waste management of the packages,

- $\quad$ Fit within a circular economy, with respect to the recyclability of the package itself and potential for using recycled content within the package,

- Expected impact on littering behaviour,

- Expected impact on the business costs for the packaging industry and retailer.

It is not the intention of this study to present a full-fledged LCA-study, since that does not fit with the financial and time constraints imposed by the project. It is, however, the intention of this study to explore the abovementioned impacts (criteria) for two groups of fresh food products.

\section{Scope}

This exploration is confined to two market segments of fresh foods :

- $\quad$ Fruits and vegetables and

- Poultry meat products. 


\subsection{Project information}

This work is performed in the project "Packaging versus food losses". It is commissioned by Foundation TKI Agri \& Food, Foundation TKI Horticulture (project number LWV190245/LWV19245). The project was financed by Foundation TKI Agri \& Food, Foundation TKI Horticulture and Wageningen Food \& Biobased Research. The research was executed independently by researchers of Wageningen Food \& Biobased Research in 2019-2020. The report is intended for packaging technologists working in food companies and packaging technology researchers. In March 2020 the project is being continued as a Public Private Partnership, with extra funding from private partners ${ }^{2}$.

\subsection{Definitions}

In this report several terms are used, for which it is important to give an appropriate definition. Abbreviations are listed separately near the end of the document.

Recycling.

We follow the definition of recycling that is given in the waste framework directive [EU 2008/98], article 3.17. 'Recycling' means any recovery operation by which waste materials are reprocessed into products, materials or substances whether for the original or other purposes. It includes the reprocessing of organic material but does not include energy recovery and the reprocessing into materials that are to be used as fuels or for backfilling operations.

\section{Recyclable}

The terms recyclable and recyclability have been interpreted in detail in the past by multiple organisations. The association of European plastic recyclers PRE has defined the four general conditions which should be met to render a plastic package recyclable: 1) the package should be collected or recovered with the intention of recycling, 2) the package should be positively sorted into a sorted product, 3) the sorted product is recycled on an industrial scale to recycled plastics, 4) the recycled plastic has a well-defined composition and is used in the production of new packages and consumer articles. Additionally, has PRE has published several general design guidelines for several types of packages [PRE website]. In the Netherlands KIDV has published recycle checks with decision trees [KIDV website]. Both the PRE and KIDV qualify packaging designs in multiple categories: good, mediocre and bad. Since there are several components that reduce the quality of the recycled slightly or for which it is difficult to establish its effect on the quality of the recycled plastic unambiguously. Nevertheless recyclable is a property of a package that depends on the purpose of the recyclingoperation and the recycling technologies that are available to achieve the objective. This implies that packages can be evaluated as recyclable in one country and as non-recyclable in another country, since both the recycling technologies used and the intention of the recycling system can differ between countries.

\section{Circular recycling / circularity}

Although there are hundreds of definitions of the term 'circular economy' in general [Kirchherr et al. 2017], there are very few of 'circular recycling'. Our interpretation of this term is the recycling of an object to a similar type of object with a comparable level of technical complexity. Hence if we apply this term on plastic packages, the circular recycling of a plastic package means that the recycled plastic is used to make new plastic packages or related plastic consumer articles of a similar complexity.

\footnotetext{
${ }^{2}$ Samen Tegen Voedselverspilling (Secretary), Kennisinstituut Duurzaam Verpakken (KIDV), Federatie Nederlandse Levensmiddelen Industrie (FNLI), Centraal Bureau Levensmiddelenhandel (CBL), GroentenFruit Huis (GFH), Nederlandse Rubber- en Kunststofindustrie (NRK)
} 
Single-use plastics

There is no clear definition of the term single-use plastics. In some websites it is defined as disposables. In this report a single-use plastic article is an article that is completely or predominantly made from plastic, has a very short effective use time of less than 1 hour and is discarded directly after use. In the annex of the EU directive [EU 2019 914] several items are listed that are regarded as SUPs: balloon sticks, cotton bud sticks, disposable tableware, beverage cups, etc. but also food containers used to contain foods for direct consumption, in case they are not part of an EPR scheme.

Regrettable replacement

A regrettable replacement is an alternative packaging type, which appears to be causing less environmental impacts, but instead behaves as a contaminant in the local waste management infrastructure and consequently actually is less environmental friendly than perceived. These regrettable replacements are often the result of superficial packaging management by stakeholders that want to implement a quick fix and judge environmental perception as more relevant than environmental impacts. 


\section{Methods}

To describe the currently used packages and the alternatives, first interviews were held with representatives of involved food industries, the packages were disassembled and their material compositions were described and lastly the packages were assessed in relation to seven indicators.

\section{$2.1 \quad$ Interviews}

Interviews were held with various incumbents from the food-packaging chain, such as representatives of food packaging industries, packaging producers and retail and trade organisations, see annex 2 . Some incumbents did not want to be named in this report and hence their input was treated confidential. Especially food loss, amounts of waste generated, production capacity data, and costs are considered to be sensitive data, which several incumbents did not want to disclose. These interviews were used to describe the most commonly used packages, their benefits and their issues in daily operations. Also the dilemmas the incumbents experience in proceeding towards a more circular economy for plastic packages were discussed: the options for material reduction, use of alternative materials, the current shelf life and food loss and the factors affecting that, the recyclability of the current packages and the options to improve it. Based on these interviews a reference package was chosen for each of the studied markets, along with several alternative packages.

\subsection{Analysis of the packages}

The material composition of the commonly used packages was studied by taking packages from the market, removing and weighing the food contents. The emptied packages were cleaned and dried. These packages were photographed and their dimensions were measured. Subsequently the packaging components were carefully disassembled with a scalpel knife and a pair of scissors. All the components were separately weighed and the main material was identified visually. To identify the polymer type of plastic components, a NIR sensor (IOSYS SIRO) was used. The material composition of all the studied packages are listed in Annex 1.

\subsection{Packaging assessment}

The reference and the alternative packages were evaluated with respect to the evaluation criteria listed below. These criteria have been chosen to evaluate the packaging performance, the environmental impact, their impact on the recycling chain and their suitedness for a circular economy of plastic packages.

Evaluation criteria for the food packages:

- Plastic use per unit of packaged product in $\%(w / w)$,

- Estimated environmental impact as expressed in terms of greenhouse gas emission potential over 100 years (GWP-100) in $\mathrm{kg} \mathrm{CO}_{2}$ eqv./kg packaged product,

- Business costs for packaging industries (qualitatively expressed),

- Business costs for retailers (qualitatively expressed),

- Recyclability indicator, expressed as the fraction of the weight of the package that can be recycled $\%(w / w)$,

- Circularity indicator, expressed as the fraction of the weight of the package that can be recycled circularly $\%(\mathrm{w} / \mathrm{w})$,

- Littering Prevention indicator, indicatively expressed with a dedicated indicator (\%), see section 2.3.6. 


\subsubsection{Plastic usage}

The plastic usage per unit of packaged product is determined by weighing the plastic components of the package and divide it by the product weight. It is expressed in $\%(\mathrm{~m} / \mathrm{m})$.

\subsubsection{Environmental impact of the food-packaging systems}

The environmental impact of the total food - packaging system is calculated according the method of Wikstrom et al. to incorporate food waste and loss into environmental impact [Wikstrom et al. 2014], with some minor elaborations. The functional unit is $1000 \mathrm{~kg}$ of consumed foods $\left(\mathrm{m}_{\mathrm{CF}}\right)$. But since there are many losses in the food production chain, the amount of produced food is much larger $\left(\mathrm{m}_{\mathrm{PF}}\right)$. The mass of produced foods equals the mass of consumed foods divided by the fraction of foods that is consumed, which in turn equals $100 \%$ minus the loss factor $(L)$, see equation 1 .

$$
m_{P F}=\frac{m_{C F}}{(1-L)}
$$

\section{Equation 1 Relation between the mass of consumed foods, the mass of produced foods and the loss factor}

All the relevant food losses and wastes are accounted for in the loss factor. In this study, the focus is on the losses of the packaged food products and hence the loss factor is the sum of the losses at the households and the losses at the retailer.

The total environmental impact of the food-packaging system (TEI) then equals the sums of the impacts of the produced foods $\left(E I_{P F}\right)$, the produced packages $\left(E I_{P}\right)$, the packaging waste management $\left(E I_{W P}\right)$ and of the packaged foods that were wasted $\left(E I_{W F}\right)$. This total environmental impact can be calculated for any desired type of impact. In this report, the TEI is calculated with the potential for greenhouse gases after 100 year, which is approximated with emission factors. For the sake of simplicity, the environmental impact of the wasted foods is treated as if they were not packaged and the food wasted at the retailers and the consumers is treated similarly. The environmental impact of the wasted food then equals the impact factor for the treatment of the wasted food (IFWP) multiplied by the mass of foods produced and the loss factor.

$$
T E I=E I_{P F}+E I_{P}+E I_{W P}+E I_{W F}=E I_{P F}+E I_{P}+E I_{W P}+I F_{W F} \times m_{P F} \times L
$$

Equation 2 The total environmental impact equals the sums of the contributions of the produced food, the packages, the waste handling of the packages and of the wasted food

The functional unit will be $1000 \mathrm{~kg}$ consumed foods and hence the total environmental impact has to be divided by the functional unit (a mass of $1000 \mathrm{~kg}$ consumed foods), as Wikstrom et al. have already shown, by combining equations 1 and 2 then equation 3 is obtained.

$$
\frac{T E I}{m_{C F}}=\frac{E I_{P F}+E I_{P}+E I_{W P}}{m_{C F}}+I F_{W F} \times \frac{\left(m_{P F}-m_{C F}\right)}{m_{C F}}
$$

\section{Equation 3 Total environmental impact of food-packaging system per functional unit}

The environmental impact of the waste management of the packages can further be expressed by taking the impact factors for recycling and multiplying that by the share of packages that will be recycled and the impact factor for incineration with energy recovery and multiplying that by the share of packages that will be incinerated. These shares of packages that follow a certain waste management pathway are named End-of-Life factors and are taken from recent publications [Brouwer et al. 2019]. Since packages are usually multi-component articles also this material composition is accounted for in this calculation.

The values for all the impact factors, End-of-Life factors and their sources are listed in annex 1. 


\subsubsection{Business costs for the packaging industry}

The business costs for the packaging industries were qualitatively estimated based on the packaging price and operational costs associated with the packaging, such as production capacity. These were qualitatively summarised in the following indicators: 0 no real noticeable effect on the business costs, + slightly higher business costs, ++ strongly higher business cost, - slightly lower business cost and -

- strongly reduced business cost.

\subsubsection{Business costs for the retail organisation}

The business costs for the retailers were qualitatively estimated from the fees the retailer has to pay to the extended producer responsibility organisation in the Netherlands [Afvalfonds, 2020] and from the expected impact on the sales. These were qualitatively summarised in the following indicators: 0 no real noticeable effect on the business costs, + slightly higher business costs, ++ strongly higher business cost, - slightly lower business cost and - - strongly reduced business cost.

\subsubsection{Recyclability indicators}

In this report two recyclability indicators are reported, the recyclability indicator and the circular recyclability indicator. Both vary from 0 to $100 \%$, from non-recyclable to completely recyclable. The recyclability indicator $(R I)$ is a product of a binary operator $(\varphi)$ and the weight share of the main component from the package that is targeted for recycling. The binary operator $(\varphi)$ describes whether or not the package is recyclable according to the state of the recycling industry. Hence, the recyclability indicator equals the theoretical maximally achievable recycling rate for the package, in case it is completely collected, sorted and recycled, see Equation 4.

$$
R I=\varphi \times \frac{\text { Retrieved mass of package after recycling }}{\text { total mass of the package }}
$$

\section{Equation 4 the recyclability indicator is calculated from a binary operator that describes if the package is targeted for recycling $(\varphi)$ and the mass share of the package that is retrieved after recycling}

The circular recycling indicator (CRI) describes whether or not the material inside the package can or cannot be recycled into the same package again and comply with all the regulations. This indicator is a product of a binary operator $(\rho)$ and the mass share of the package that is retrieved after recycling. The binary operator describes whether or not the package will be circularly recycled.

$$
C R I=\rho \times \frac{\text { Retrieved mass of package after recycling }}{\text { total mass of the package }}
$$

\section{Equation 5 the circular recyclability indicator is calculated from a binary operator that describes if the package will be recycled circularly $(\rho)$ and the mass share of the package that is retrieved after recycling}

\subsubsection{Littering prevention indicator}

Although a littering indicator has already been published [Civancik-Uslu et al. 2020], it was decided to use a different one. First of all, the published indicator is fairly complicated and is specific for a certain packaging type (carriage bags). Secondly, for the sake of comparison with other indicators, we would like a reverse indicator: one that is $0 \%$ when it can be expected that all articles will be littered and is $100 \%$ when none of the articles will end up in the nature. We combined three factors in the littering prevention indicator (LPI): 1) Is the article commonly used out-of-home?, 2) Is the article a commonly known SUP and listed as commonly found on European beaches?, 3) the mass share of non-degradable materials of the packages. In case the article is commonly used out-of-home the binary indicator is 1 , otherwise when predominantly used in home a 0.5 . In case the article is positively listed on the SUP list then this binary indicator is 1 otherwise 0.5 . These two binary indicators with the mass share of non-degradable materials (materials that are expected to degrade 
within one year in a moderate climate) are used to calculate the littering prevention indicator, see equation 6 .

$$
L P I=100 \%-\left(B I_{\text {use }} \times B I_{\text {SUP }} \times c_{\text {non-degradable }}\right)
$$

\section{Equation 6: Littering prevention indicator}




\section{$3 \quad$ Fruit and vegetables}

The use of plastic packaging for fresh fruits and vegetables has increased largely over the past thirty years. The drivers for this increased use in plastic packaging have been diverse: improved hygiene, marketing opportunities, faster handling at the counters and raising the shelf life. Therefore this fresh food market segment is well-suited to reduce the use of plastic packages. Though large, it is also a fragmented market, with strongly varying packaging needs per product group. Hence, dozens of dedicated improvements can be defined for different products. After a general introduction to show the opportunities for more sustainable packages in the fresh fruit and vegetable market, one specific example is studied in detail: that of snack tomatoes.

\subsection{Overview of opportunities}

Multiple overviews of the packaging technologies for fresh fruit and vegetables have been written and this heterogeneous product group can coarsely be divided in the categories detailed below [Robertson, 2013]. Nevertheless, the need to use packages and the selection of the least impactful package per product is still a case-by-case decision.

Large whole individual fruit \& vegetables (watermelon, pineapple, pumpkin, coconut, celery root, whole cabbages, etc.) do not need a plastic package to extend their shelf-life. Within supermarkets they need labels with bar codes or with information relating to their origin and production method (organic or regular). A new development is to laser etch this information in the fruit skin, which has been developed by the organic trading company Eosta together with Spanish and German laser machine manufacturers. This is named 'natural branding', is a freely available technology, and works with many types of fruit skin, but not with all. Anyhow, when possible it can reduce the use of plastic labels, significantly for this category [Natural branding, 2020].

Some whole vegetable products are susceptible to dehydration and shrivelling, such as lettuce crops, pak choy and cucumbers. For lettuce crops and pak choy this can be solved by open PE based sleeves and increasing the relative humidity of the counter with spraying and misting technologies.

Medium sized hard fruit \& vegetables (citrus fruit, apples, pears, mangos, avocados, bell-peppers, onions, bananas, etc.) are either sold loose, or bundled in nets, trays and flow-packs. In case they are sold loose, most supermarkets provide light weight PE-based bags. A few supermarkets test reusable fruit bags. Others bundle these fruits in nets. Anyhow, these PE bags, moulded fibre trays, folding carton trays and PP trays are recyclable. The situation is less clear for the stretch-wrap or flow-pack around the trays and nets. PVC stretch-wrap is not recyclable, nets are generally not recyclable. PEbased stretch-wrap is potentially recyclable and flow-packs are made from PP films which are currently predominantly recycled to Mix (which does represent an environmental benefit but does not fit in a circular perspective). Products that are sensitive to dehydration (bell peppers) still need a package to avoid shrivelling. The products that are less sensitive to dehydration might better be sold loose and when necessary branded to label the products. In case of bananas a sticky wrapper is sufficient to bundle and identify a bunch.

Soft fruit \& vegetables (strawberries, red currents, raspberries, blueberries, tomatoes, peach, nectarines, grapes, etc.) are usually sold in trays and clamshells. These products are fragile and susceptible for damages to the skin and bruises which are usually followed by mould growth. A small share of these products are packed in equilibrium modified atmosphere packages, hence top-sealed trays with a well-defined number of micro-perforations in the lid. Most of these products are sold in PET trays, punnets, clamshells and macro-perforated top-sealed trays. The PET trays are still waiting for a recycling technology (three companies are busy developing such a technology). A smaller fraction is sold in folding cartons and moulded fibre trays with PP-film flow-pack.

Leafy vegetables and minimal processed products (spinach, cut iceberg lettuce, endive, mixed salads) are usually packed in gas-flushed PP-flow-packs. Additionally several luxury salad products which also 
contain other food components (cheese, nuts, dressing, etc.) are usually sold in PET trays with a modified atmosphere. The PP-films are currently recycled into Mix-products. The PET-trays are waiting for a recycling technology. The packages are required to contain the product and to protect the products against shrivelling (dehydration) and discolouration.

In short, this concise overview shows that there are multiple strategies to reduce the amount of plastic packages for whole products and when indispensable for small, soft and processed fruit \& vegetable products there are potentially options to replace the packages with recyclable alternatives.

Nevertheless, the need for a package has to be established case-by-case and if required, the least impactful package has to be selected carefully. In the following section the options for snack tomatoes are discussed in a detail.

\subsection{Snack tomatoes}

\subsubsection{Performance indicators}

Snack tomatoes are largely sold on the Dutch market in plastic shakers with 250 gram product weight (S1-S3 in figure 1) and in plastic buckets with 500 gram product weight (B1 and B2 in figure 1). Depending on the season, these snack tomatoes originate from Dutch greenhouses, or Spanish and Moroccan fields and are packaged locally. All packages have macro-perforations for gas and moisture exchange. The macro-perforations do not limit the moisture loss and also do not influence the gas exchange and hence have no influence on the keepability and shelf-life. The vegetable companies that we spoke do not register food losses in supermarkets. Their information on the subject is, although anecdotical, still insightful.

Three clear examples of attempts to improve the sustainability and circularity of these packages have been observed on the Dutch market.

First of all, EOSTA wanted to differentiate organic snack tomatoes from regular snack tomatoes with help of the package. Therefore, it tested various formats of folding carton (made from bagasse, the fibrous side-product of the sugar cane industry) boxes and paper based cups. These fibre based packaging formats are optically non-transparent, which disables potential consumers to judge the quality of the tomatoes on the point of sales. To overcome this disadvantage, either holes are punctured in the side wall or a plastic (PLA) window is inserted in the side wall (packages CB1, CB2 and $\mathrm{CB} 3$ ).

Secondly, several German retailers use a classical milkshake-package for the organic snack tomatoes, composed of a PE-coated paper cup with a PET based hemispherical lid (package CS1).

Thirdly, the Dutch retailer Plus uses a transparent PP-based stand-up pouch to sell regular snack tomatoes (package SP1).

One of the supermarket chains that EOSTA supplies, tested the fibre based boxes with the PLA windows in the summer months of 2019 (CB2 and CB3). This resulted in a loss in sales volume of 30 $\%$. After 5 months the retailer decided to revert back to plastic shakers (S1) and the sales regained their original volume. This situation is exemplary for the hesitation of retailers to offer snack tomatoes in packages that might have a lower environmental impact but also restrict the visibility of the product and hence could result in lower sales.

It is important to note that the drop in sales volume cannot be attributed only to the change in packaging format, since the change in packaging type coincided with a large over-supply of fresh product in the summer of 2019 , with consequently low priced regular snack tomatoes as competitors. A much more controlled experiment is needed to assess the impact of product visibility on the sales volume directly after introduction and after a year to see if they recover and consumers get accustomed to the new packaging format in the long run. Nevertheless, this example clarifies a general dilemma for fresh food packaging companies wanting to improve the sustainability of packages: many consumers want to visually inspect the quality of the product at the point of sale and hence the package needs to be optically transparent. 


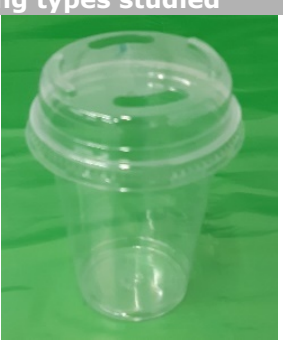

S1 PET based

Conventional buckets

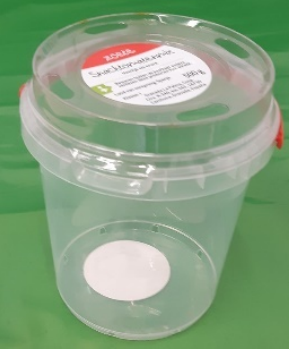

$\mathrm{B} 1$ (PP, PET lid)

Cardboard (bagasse) boxes

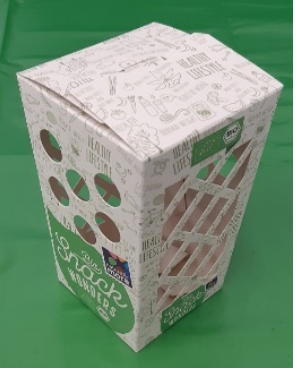

CB1

Paper cup shaker

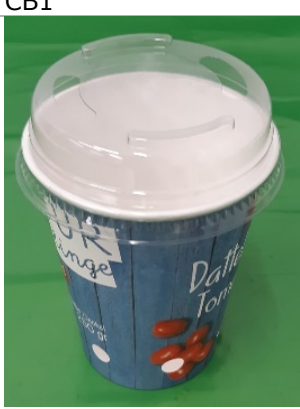

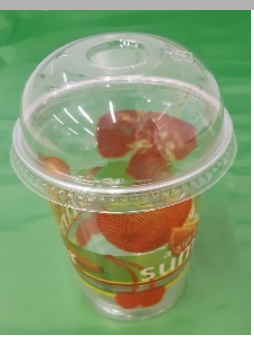

S2, PET based

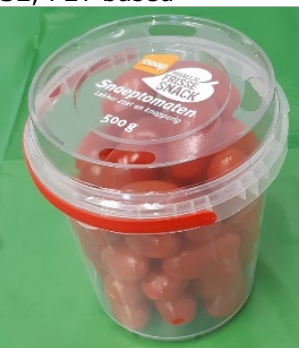

B2 (PP, PET lid)

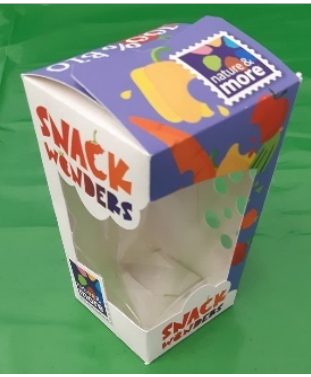

CB2

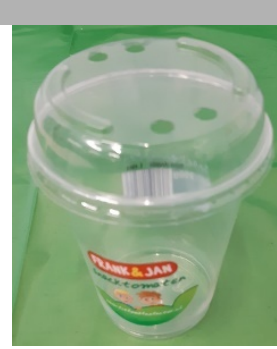

S3, PP cup and PET lid

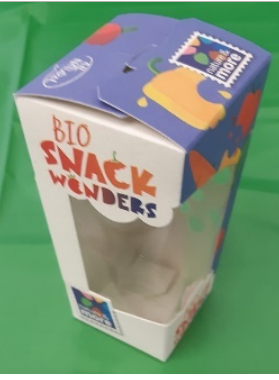

CB3

CS1 coated paper \& PET

Stand-up pouch

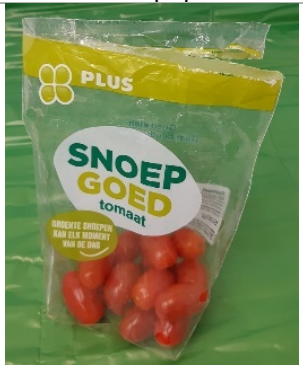

SP1 (PP)

\section{Figure 1}

The packaging types studied for snack tomatoes

The dilemma between the need for optically transparent packages to generate sales and environmental sustainability is widely recognised by fruit and vegetable traders. For example, the Jumbo supermarket van der Graaf in Soest has experimented by offering the same tomatoes, mushrooms, etc. in plastic and cardboard trays side by side and reported a 80:20\% ratio in the sales between the plastic and cardboard tray, respectively [Anon. 2020].

The retailer organisation Plus is offering the snack tomatoes in the transparent PP stand-up pouches and reports a clear growth in sales with the introduction of this new packaging format in a combination with related products and a more attractive display position in the shops. It is unknown 
which factor contributed most to the growth in sales, but it is likely that this minimal-plastic packaging design contributed to persuade consumers that otherwise would have felt that the buckets and shakers were too lumpy plastic packages. The retailer also reports that the downside of the stand-up pouch was the vulnerability of the fruits during logistics and shelf filling. Several adjustments were necessary in the supply chain to minimise food loss. With these adjustments there is currently no evidence for increased food loss rates in the supermarkets.

The approximated environmental impact for the snack-tomato packaging combinations are given in Figure 2. The codes of the packaging types are explained in Figure 1. The calculations have been made with major assumptions regarding the production method of the tomatoes and the level of food loss and waste and hence the results are only indicative. To understand this sensitivity better, a limited sensitivity analysis was performed, which revealed that the results are mostly affected by the global warming potential that is related to the production of the tomatoes (annex 3 ). Although the results should be treated as indicative results, still these results give several interesting insights.

\section{GWP-100, [kg CO 2 eqv/1000 kg food consumed]}

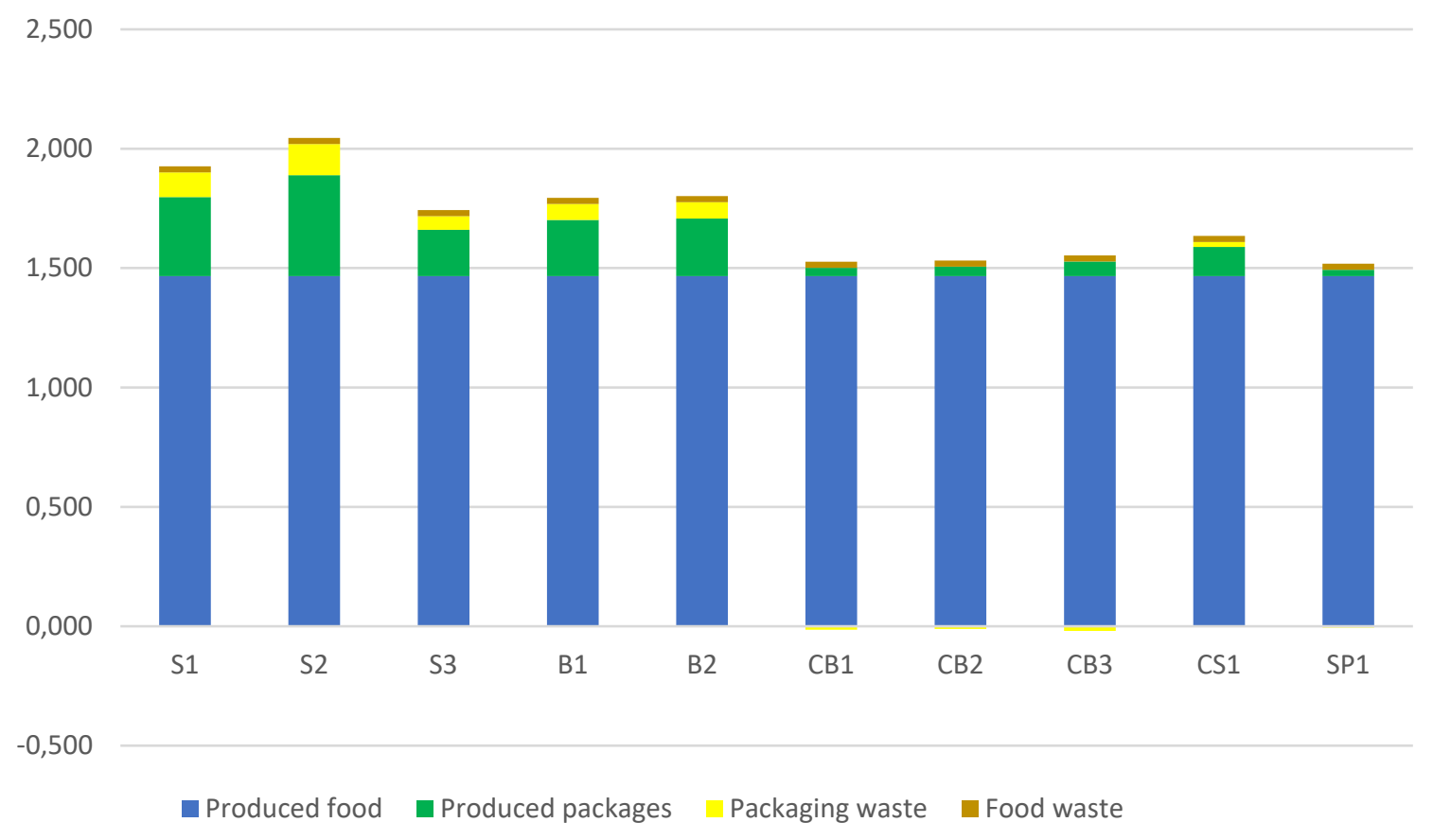

\section{Figure 2 Total environmental impacts of the packaged snack tomatoes in 10 different packaging types with respect to the global warming potential in 100 years' time, expressed in $\mathrm{kg} \mathrm{CO}_{2}$ equivalents per $\mathrm{kg}$ snack tomatoes consumed}

First of all, the environmental impact of the production of the tomatoes exceeds the impact of the production of the packages. For the production of $1128 \mathrm{~kg}$ snack tomatoes (needed to consume 1000 $\mathrm{kg}$ at a food loss rate of $4 \%$ at the retail and $8 \%$ at the households) in greenhouses $1466 \mathrm{~kg} \mathrm{CO} 2$ eqv. are emitted. To package this amount of tomatoes 2256 to 6445 packaging units are needed. The production of these packages results in an emission of 35 to $423 \mathrm{~kg} \mathrm{CO}_{2}$ eqv. The lower emission values relate to the fibre based packages, the higher values to the PET based shakers. Hence, the relative contribution of the packages to the $\mathrm{CO}_{2}$ emission varies between 2 and $21 \%$. This relative contribution will grow when the tomatoes are produced in open fields, as the emission factors for tomato production will roughly halve in value [Theurl et al. 2014].

The relative contribution of the waste management of the packages and the wasted food is relatively small. Only for plastic packaging the contribution of waste management can reach levels of $6 \%$ to the emission.

The relative GWP-100 values (relative to the reference packaging S1) and the values of the other indicative packaging performance indicators are listed in table 1 and shown in Figure 4 . These 
packaging performance indicators reveal that the smaller PET based packages (S1 and S2) for the snack tomatoes have a relative high impact on the global warming potential and are also not optimal with regard to the prevention of littering. On the other hand, only these PET-based shakers can in the future be recycled in a circular fashion and they allow the consumers to visually assess the product at the point of sale and therefore generate relatively high sales volumes.

Table 1 Overview of all the packaging performance indicators. $R I$ is recycling indicator, CRI is circular recycling indicator and LPI is litter prevention indicator.

\begin{tabular}{|c|c|c|c|c|c|c|c|}
\hline Code & $\begin{array}{c}\text { Plastic - } \\
\text { product ratio }\end{array}$ & $\begin{array}{c}\text { Relative GWP- } \\
100\end{array}$ & BC packer & BC retailer & RI & CRI & LPI \\
\hline $\mathrm{S} 1$ & $5 \%$ & $100 \%$ & 0 & 0 & $0 \% / 99 \%{ }^{+}$ & $0 \% / 99 \%{ }^{+}$ & $75 \%$ \\
\hline $\mathrm{S} 2$ & $7 \%$ & $106 \%$ & 0 & + & $0 \% / 99 \%^{+}$ & $0 \% / 99 \%^{+}$ & $75 \%$ \\
\hline S3 & $5 \%$ & $97 \%$ & 0 & - & $67 \%$ & $0 \%$ & $75 \%$ \\
\hline CB1 & $0 \%$ & $79 \%$ & $0 /+$ & + & $100 \%$ & $0 \%$ & $100 \%$ \\
\hline $\mathrm{CB} 2$ & $1 \%$ & $80 \%$ & $0 /+$ & + & $87 \%$ & $0 \%$ & $97 \%$ \\
\hline $\mathrm{CB} 3$ & $1 \%$ & $80 \%$ & $0 /+$ & + & $90 \%$ & $0 \%$ & $98 \%$ \\
\hline
\end{tabular}

*: Coated paper cups can only recycled separately with paper cups and or beverage cartons and not with paper and board

+: Currently non-bottle PET is not yet recycled. However, when the recycling technologies have been developed, these packages could potentially be recycled to new packages in the future.

$\mathrm{BC}=$ Business Costs. The qualitative substantiation is given in Annex 4.

The PP-based packages (S3, B1, B2) have a slightly lower impact on the global warming potential and are expected to generate as much sales as the PET based packages, since the product can be inspected by the consumer on the point of sale. The PP-based packages can also not avoid the littering completely. The level of recyclability of the PP based packages is currently still higher than of the PET based packages. However, when a recycling technology for non-bottle-PET is developed, this situation will pivot and PET packages will then have a higher level of recyclability, since the PP-packages are not completely recycled (the sinking fraction with the PET lids is incinerated). Furthermore, the PP based packages cannot be circularly recycled into new food packages, but have to be recycled in non-food packages and other consumer articles. The PP-based stand-up pouch (SP1) has the lowest impact on global warming potential, a very low plastic to product ratio $(1 \%)$, and is still recyclable, although not circular recyclable. Furthermore, it cannot prevent littering completely.

The fibre-based packages (CB1-3 and CS1) have equally low global warming potentials as the standup pouch (SP1), the lowest plastic to product ratios and the highest littering prevention indicators. However, they are expected to impact the sales in a negative manner and although largely recyclable, fibre-based packages cannot be recycled in a circular manner to food-grade packages. 


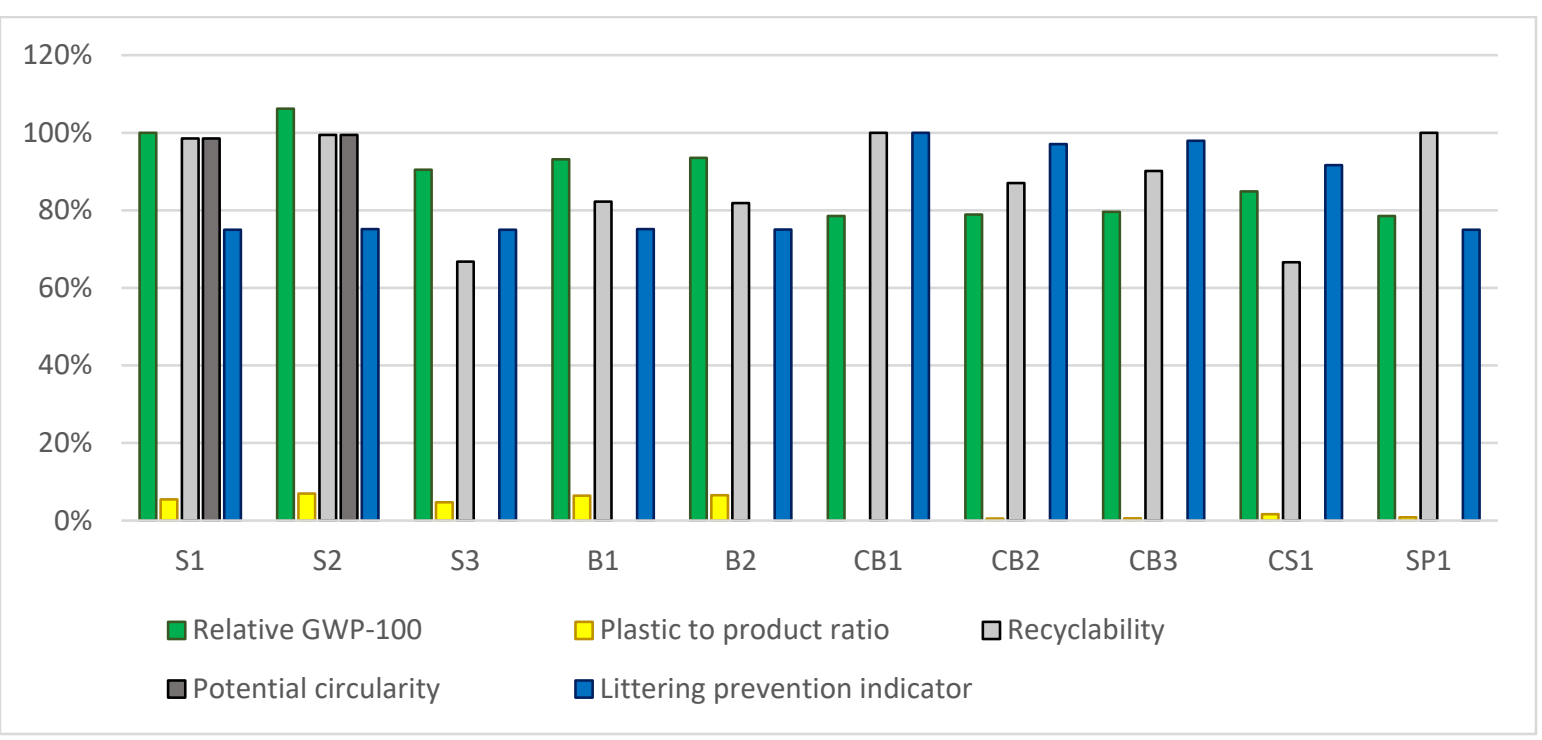

Figure 3

The relative packaging performance indicators for the snack tomato packages

This case of the snack tomatoes clearly shows a trade-off and dilemma for fresh food companies. It is not feasible to abolish the package completely, since some form of containment is required to keep the loose fruits together and the fruits will get bruises and mechanical injuries when they are not protected. So, the challenge becomes to minimise the use of packaging materials and the global warming potential and to maximise the recyclability and the littering prevention indicator, while maintaining the regular sales and business. But it is also impossible to get all these indicators optimal. Either a fibre-based package is chosen or a PP-based stand-up pouch with minimal environmental impact, but these are not circular recyclable, or a rigid plastic-based package is chosen, with higher environmental impact and for the PET based packages the future potential of being circular recyclable.

Furthermore, although the fibre-based packages are optimal with respect to global warming potential and litter prevention, they also might influence the sales of the product in a negative manner. This dilemma of optical transparency and sales versus low environmental impacts is a classical dilemma in the field of packaging and is especially valid for soft fruits and small sensitive vegetable products. Many consumers do want to assess the visual quality of the product at the point of sales and otherwise will not purchase the product.

When a vegetable company wants to lower the environmental impact of a food-packaging-system, it can take several measures to mitigate the emission of greenhouse gases most effectively. The effect of these measures on the global warming potential for over 100 years is shown in Figure 4 . The description and the codes are given below:

1. Changing the production method of the tomatoes from greenhouse to open field agriculture will have the largest impact. For the reference packaging S1 the emission can drop with a staggering 35\% (S1 -> S1-OF),

2. Reducing the food loss and waste to minimal levels could at maximum reduce the emission with another 13\% (S1-OF -> S1-OF-FW)

3. Developing and using a recycling technology for non-bottle-PET will reduce the overall emission with $6 \%$ (S1-OF-FW -> S1-OF-FW+REC)

4. Changing the packaging type from plastic shakers to a full fibre based box can reduce the emission with another 33\% (S1-OF-FW -> CB1-OF-FW). Alternatively changing the packaging type to the PP-based stand-up-pouch (SP1) has the same positive effect.

Not all these mitigation steps are taken easily. For instance, the availability of tomatoes grown in the open field depends on the season and the weather. Hence the first step cannot always be taken. Also a reduction of the food loss and waste, however desirable it may be, is not easily achieved in a society. The development of a recycling technology for PET-non-bottles is still not achieved and might take several years. But the change in packaging design and material is -at first instance- a relatively simple measure and hence attractive to be taken. 


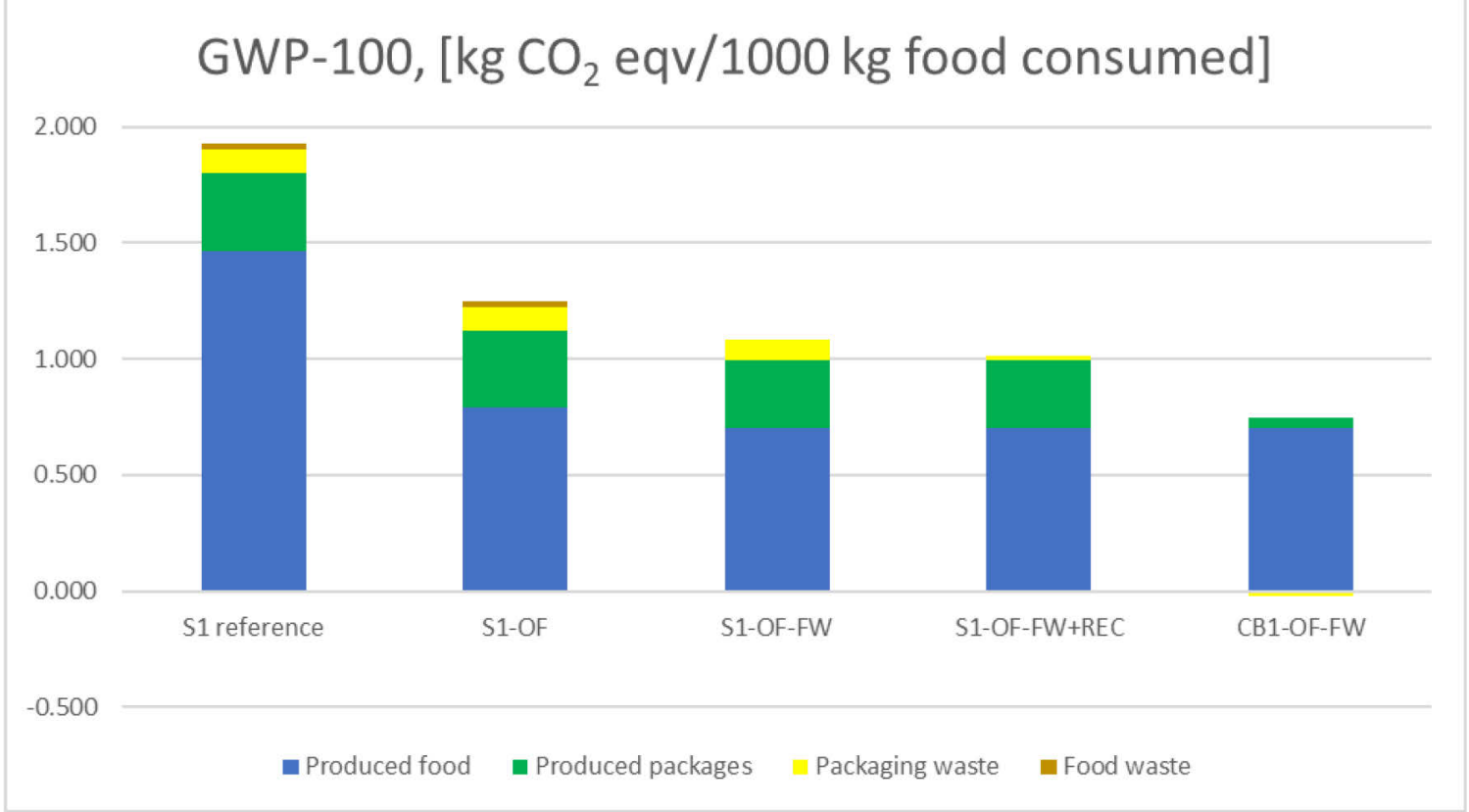

Figure 4 Effect of the scenario's to mitigate the total environmental impact in terms of global warming potential. The scenarios are described above

\subsubsection{Reflection on snack tomatoes}

The environmental impact of the production of tomatoes is much larger than of the packages. This implies that the focus should be to reduce the environmental impact of the tomato production and of food loss and wastage of the tomatoes. There are, however, uncertainties in these numbers (both related to the production, food loss and wastage). A sensitivity analysis was performed (annex 3), which revealed that the emission factor of the tomato production had the largest impact on the total environmental impact (TEI). Variations in the percentage of food loss and the End-of-Life parameters for PET packages had impacts of less than $13 \%$ on the calculated TEI. This sensitivity analysis revealed that although several input parameters have large uncertainties, the uncertainty in the final results is much smaller and the results of this study are still meaningful.

Although the environmental impact of the production of tomatoes is much larger than the production and waste management of the packages, the focus of policy makers (both national and European) is on abolishing plastic packages,. On the other hand, littering is a different form of environmental impact that would benefit from this abolishment. Littering could also be effectively reduced by using packages with the lowest plastic to product ratio, such as fibre based packages. Such packages hamper the visual quality assessment of the product by the consumer at the moment of sale and puts consumer off. Preliminary tests show that the sales volumes might decrease as a consequence. In case the sales volumes would indeed decrease, than it is likely that the food loss will increase in the shops. This has a large negative impact on the global warming potential that would outweigh the environmental benefit of the use of a fibre based package instead of the plastic based package.

Although fibre-based packages might be useful to reduce the overall environmental impact of the food-packaging system and prevent littering, they are not circularly recyclable. In case circular recycling is the ultimate goal of the policy makers then they will have to encourage R\&D to develop recycling technologies for non-bottle PET packages, and subsequently encourage collection, sorting and recycling.

The most ideal packaging type hence depends on the policy objectives, which is further explained in Table 2. Since the objectives of the various stakeholders are not aligned, no optimal packaging type exist for all stakeholders. 
From the perspective of fruit and vegetable packaging companies and retailers it is obvious that they cannot effectively make the transition towards a more circular economy by themselves. They will need the cooperation of the civilians to not litter the packages after use and enable their recycling by discarding them in the correct waste bin. Furthermore, also the investment and active participation of recycling companies is required to develop and operate recycling facilities that will recycle non-bottle PET packages into food-grade recycled PET. This will require substantial R\&D investments and since the recycling industry is a low margin industry, they need legal support from governments and financial support from multiple stakeholders, including EPR scheme operators. 


\section{$4 \quad$ Poultry meat products}

Before the turn of the century, most of the Dutch fresh meat products were sold in EPS trays with PVC stretch wrap. The bovine spongiform encephalopathy (BSE) crisis catalysed the market adoption of the modified atmosphere packaging (MAP) technology [Thoden van Velzen \& Linneman 2008]. The new packaging concept of choice became a PET-PE thermoformed tray and a PET-PE top-film with toplabel, bottom label and in some cases a drip-pad. The tray is thermoformed from PET-PE coextruded sheet with roughly a $90: 10 \%$ composition. The PET serves as a good gas barrier and maintains the protective gas mixture inside the packaging headspace for the period of the shelf life. The PE-layer makes the sealing of top-film to the tray both more fast and more reliable. Furthermore, both the tray and the top-lid are highly transparent, allowing the quality of the product to be assessed by consumers at the point of sale.

In the first two decades of the $21^{\text {st }}$ century this product-packaging-combination further developed into a system that yields 14-15 days of shelf life for most poultry meat products when refrigerated under $4^{\circ} \mathrm{C}$ (legal limit). One of the meat packers we spoke has a long lasting relationship with two large Dutch retail organisations. It receives spoilt packaged poultry meat products back from the retail shops, in case the package was damaged or not sold within the shelf life period. This gives them a very precise insight in the food losses in the retail chain. The three-year average for more than 500 Dutch retail stores is $3.55 \%$, but the variation is large (the distribution is not normal and skewed to higher losses).

Although this packaging system performs well in the current distribution system for poultry meat products, it is currently a non-recyclable package. This results in growing awareness and criticism from NGO's and stakeholders and a quest for better recyclable alternatives. Since the separate collection and mechanical recovery of plastic packaging waste started in 2009, the non-recyclable nature of these meat packages is a growing concern. Initially (2009-2011), small amounts of Dutch plastic packaging waste were collected. These wastes were sorted in Germany and the PET-based trays were added to the Mixed plastic sorting product. Most recyclers of mixed plastics are, however, only interested in PE and PP and not in PET and hence they raised the processing fees to deal with the growing amounts of processing waste, generated as a consequence of the much higher share of PET based trays in the Netherlands than in Germany. Additionally stakeholders became aware of the large amounts of "non-bottle PET packages" that were not recycled in comparison to the relatively smaller amounts of bottle PET that were recycled and began to regard this as a loss of valuable resources that could potentially be recycled back into a food-grade packaging material. As a consequence several recycling companies started to explore the options for recycling PET trays. Hitherto, none of these initiatives have been successful yet, for multiple technical and economic reasons [Thoden van Velzen, 2017].

To improve the recyclability of the meat packages, several brand-owners started with testing and or introducing alternative packages on the market, such as skin-packaging (see figure 5), mono-A-PET trays with mono-A-PET based top-film, PLA-trays with PLA based top-films, PP-EVOH-PE-trays, cartonplastic-laminated trays, etc.

\section{Skin packaging}

Various attempts to skin package poultry meat products (chicken breasts filets, legs and thighs) did not result in shelf-life extensions in comparison to the conventional MAP technology. Due to the lower production capacity of skin packaging machines as compared to MAP machines and hence the higher operational costs, this technology was not adapted for common poultry meat products. For dedicated poultry meat products such as marinated meats, barbecue-products and shish-kebabs, the skinpackaging technology resulted in higher sales, presumably due to the more attractive appearance of skin-packed marinated meats (In this case the marinade masks the discoloration of the meat in the skin-package). Skin-packaging technology is currently almost exclusively used for barbecue 
specialities in poultry meat. Since the skin packaging technology is hardly used for normal poultry meat product and since this package type is also not recyclable, it is not further analysed.

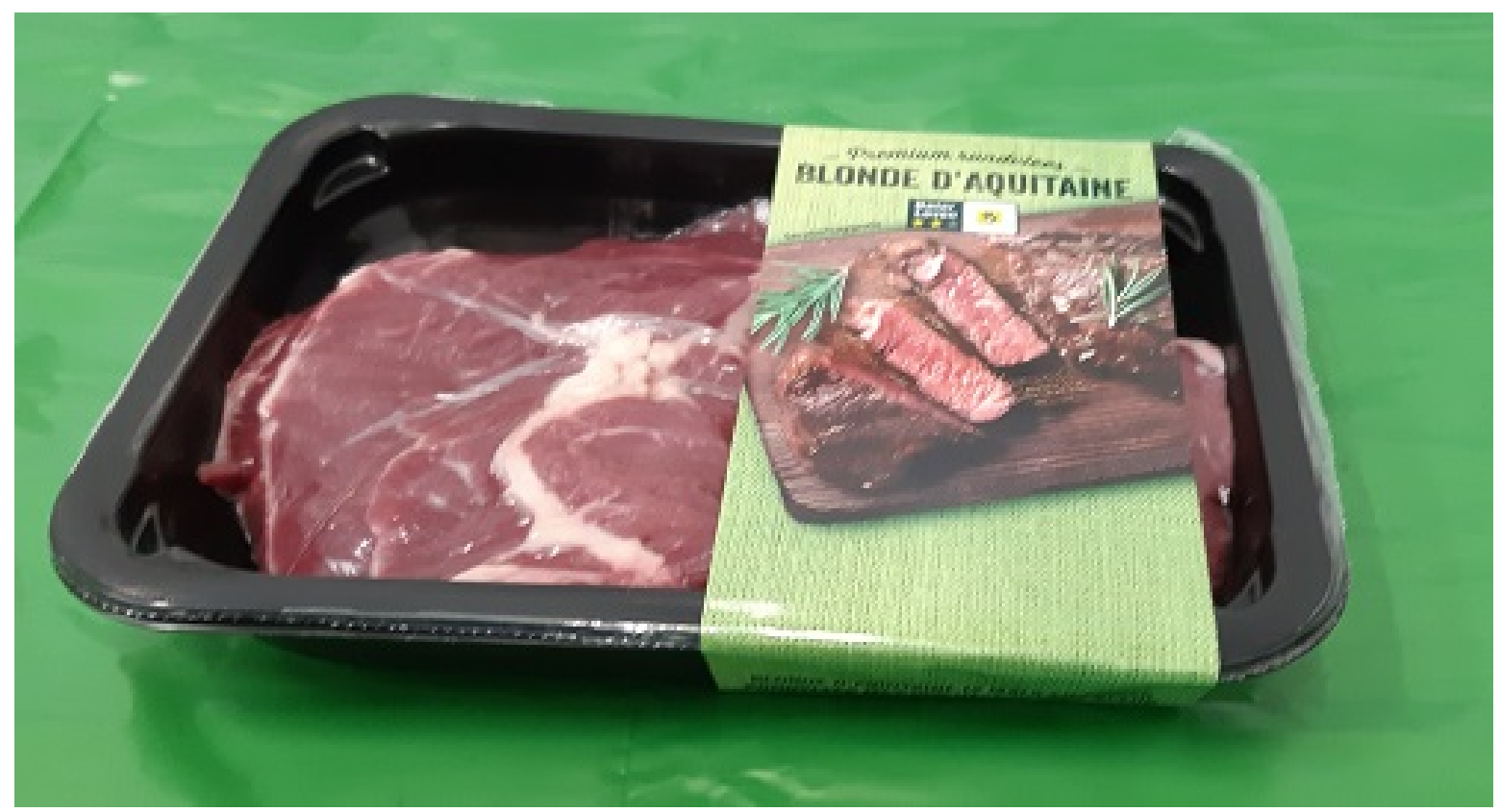

Figure 5

Picture of an skin-package of a beef product on the Dutch market

Mono-A-PET

Various so-called "Mono-A-PET trays" were also tested and used by multiple meat companies. Tests with mono-A-PET trays that are made from $100 \%$ PET (and hence without sealing coating on the flange) were not so successful. A dedicated PET top-film is used with a modified PET type as sealing layer. To seal such a top-film on a PET tray, longer sealing times (1-2 s) and more elevated temperatures (approx. $200^{\circ} \mathrm{C}$ ) are needed to obtain a well-sealed package, in comparison to PET-PE trays $\left(140-150^{\circ} \mathrm{C}\right.$ for $\left.0.2-0.5 \mathrm{~s}\right)$. Additionally the chance of a gas leakage is substantially larger; for PET-PE trays this chance is roughly estimated $0.1 \%$, but for mono-A-PET trays it can be as high as 2$4 \%$. To stop packages with leaks to enter the distribution and cause spoilage and complaints, the packages are visually inspected by an employee directly after the packaging machine. By pressing on the top-film and feeling the compression resistance of the package, employees are able to detect packages with larger leaks. The small leaks cannot be detected in this manner. Although automatic gas leakage detection systems are available, they are costly and they often haven't got the required speed of operation. Hence, such less reliable sealing systems will always cause a rise in food waste and loss, additional hassle and most importantly an additional food safety risk (which obviously translates itself in a business liability risk). The precise share of leak packages after the manual inspection is not known, but estimated to be around $2 \%$. Therefore, $100 \%$ pure mono-A-PET trays are to the best of our knowledge currently not used by (poultry) meat companies.

\section{$P E T-P E / F I$}

Mono-A-PET trays with a modified PE layer on the flange are being used by meat companies. These trays are named "Mono-A-PET" in the trade, but possess a thin layer of modified PE that has been deposited on the sealing flange and hence these trays also have a multi-material composition. The PEconcentration of these trays are difficult to measure. We estimate the PE share to be $2 \%$. We will name those trays PET-PE/FI. Companies using these trays report very low leakage chances, comparable to those of the conventional PET-PE trays. Both PET-PE and PET-PE/FI trays are roughly $10 \%$ more expensive than true mono-A-PET trays, but the increased reliability of these trays translates in lower business costs overall.

PLA trays

In 2017 retailer COOP, meat company Promessa and Holland Bioplastics released a completely compostable meat-packaging based on PLA [COOP, 2017]. It was certified as industrially compostable and civilians were advised to discard these packages with the organic waste. It was used to package 
organic meat products and was coloured green to simplify the distinction. The prime reason for this introduction was the absence of a recycling option for the PET trays and the renewable nature of the PLA feedstock. Multiple changes were made to the composition of the PLA-based top-films to allow for good anti-fogging and high transparency. The trays are approximately double the price of conventional PET-PE trays. These trays were also found to have a higher chance of leaking. This varies from about $1-2 \%$ in an automatic tray sealing machine with for instance bricks of minced meat, to $3-4 \%$ in a manually operated sealing machine with muscle meat parts. This could not be reduced and hence it was decided in 2020 to stop with the PLA trays.

Multiple stakeholders responded negatively to this new PLA-based packaging format. Waste companies claimed that it resulted in more polluted organic waste [VA, 2018]. Laborious waste analysis proved that the organic waste was polluted with fossil plastics, glass and metals, but not with PLA-meat trays ${ }^{3}$ [Zee van \& Molenveld, 2020]. Moreover, of the limited PLA-meat trays that were retrieved, most were found in the lightweight packaging waste (LWP) collection system. Since, the PLA trays do currently not contribute to one of the sorted plastic product, their presence in the LWP was found not to contribute positively to the recycling system. This formed the second reason for Promessa to stop with the PLA meat trays in 2020, and start with PET-PE/FI trays with recycled content.

\section{PP-EVOH-PE trays}

In Germany most of the meat is packaged in PP-based trays with an EVOH gas barrier layer and a PE sealing layer with a PET-PE top-film. Due to intensive trade between the Netherlands and Germany therefore also poultry meat packaged in Germany is sold on the Dutch market and hence also these PP based trays are used. The recyclability of these trays has not been studied independently yet, as far as we are aware. We presume that they will be recycled with the DKR 324 sorted product for polypropylene (named DKR 324) and cause a slight polymer contamination of EVOH, PE and PET of the recycled PP material.

Alternative trays, made of PE-EVOH-PE film laminated on cardboard [Halopack, 2020], are as far as we are aware currently not used for poultry meat on the Dutch market. The production capacity for these laminated cardboard trays is still limited and mostly used for pasteurised meals.

Furthermore, in the last years, all manufacturers of PET trays (both conventional PET-PE and PET$\mathrm{PE} / \mathrm{FI}$ ) started to offer also trays with recycled content. This recycled content partly originates from inhouse production waste and also from recycled PET bottles. Levels of recycled content in PET trays are now commonly $50 \%$, but variation exist.

Photographs and codes of all the studied (poultry) meat packages are shown in Figure 6.

\footnotetext{
${ }^{3}$ It is very difficult to prove empirically that a certain package is absent in a waste stream, as it would require an enormous effort of sorting many samples of this waste stream. Nevertheless, this analysis did show clearly that many other contaminants are present in meaningful concentrations and hence that the focus on the PLA meat trays is not justified.
} 


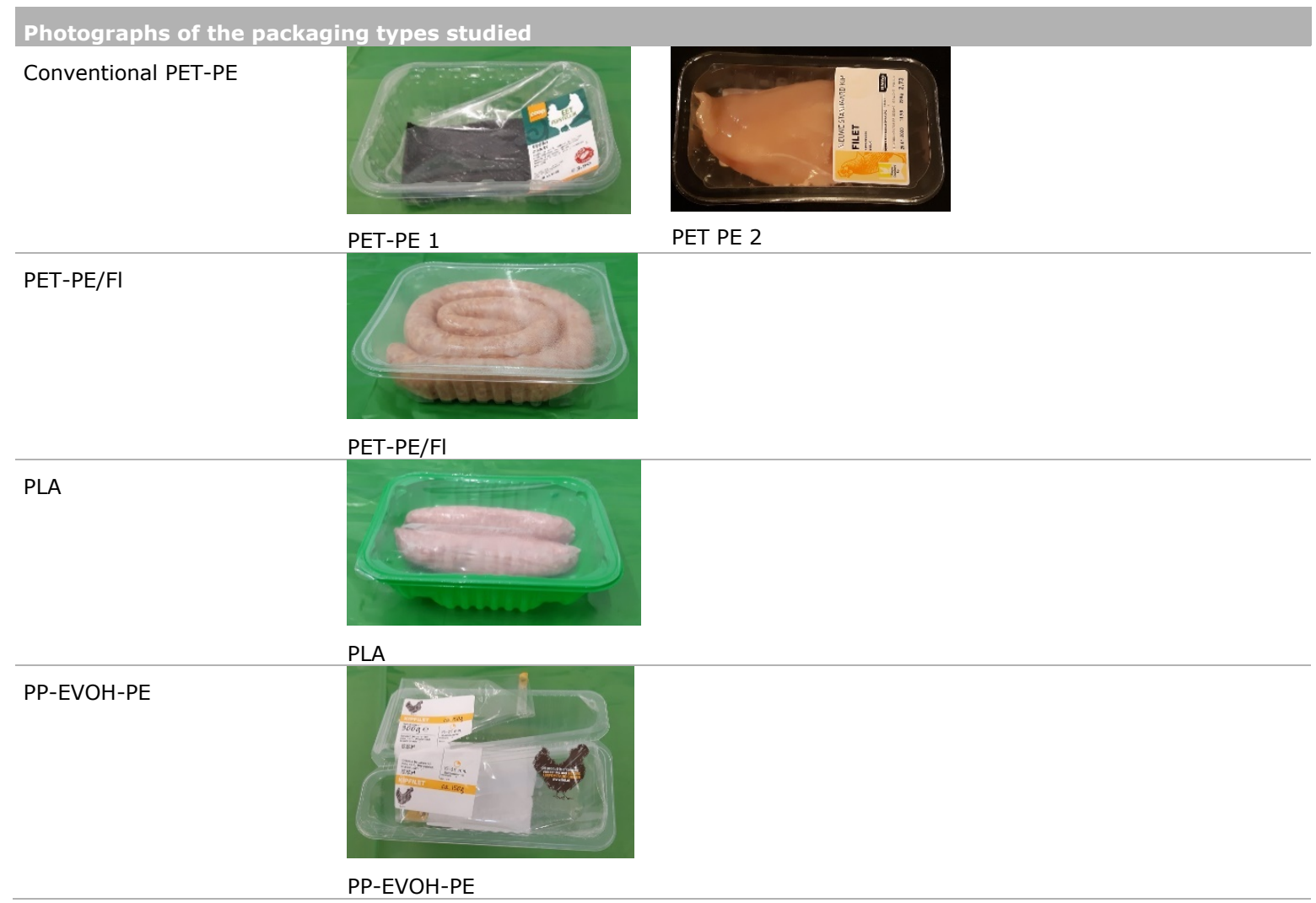

Figure 6 The packaging types studied for poultry meat

The calculated environmental impact for the poultry meat packaging combinations are given in Figure 7. The codes used refer to the type of tray that is being used. Two variants of the PET trays are calculated, one with virgin PET and one with 50\% recycled content. The latter is indicated with " $50 \%$ $\mathrm{RC}^{\prime \prime}$ in the code. The calculations have been made with major assumptions regarding the production method of the poultry meat, the level of food loss and waste and hence the results are only indicative. Nevertheless, again these indicative results give several interesting insights.

As expected the net greenhouse gas emissions that are related to the production of the poultry meat are much larger than the emissions related to the package and the waste handling. Most packaging formats have hardly any impact on the shelf life of the packaged product and hence not on the food loss and waste. The packages also have hardly any impact on the total net greenhouse gas emissions of the meat-packaging system. Only for the PLA package, the food loss is estimated to be $1.5 \%$ higher and hence more poultry meat has to be produced to achieve the functional unit of $1000 \mathrm{~kg}$ poultry meat consumed. This is compensated by the lower environmental impact for the production of the PLA meat trays, causing the overall environmental impact to be fairly similar between the various packaging types.

The three PET trays with $50 \%$ recycled content have, as expected, a lower environmental impact than the three PET trays with virgin PET. The packages PET-PE2 and PP-EVOH-PE have a slightly higher environmental impact. These are, however, specially portioned packages. These packages are intended for the smaller households (1-2 persons) and hence have a slightly higher product to packaging weight ratios, which affects the environmental impact slightly negatively. No food loss and waste numbers are available per packaging type and portion size, but it is possible that due to this smaller portion size, the food loss and waste number is actually slightly lower, which might compensate for the slightly higher environmental impact of the packages. Unfortunately this is unknown and remains speculation. 


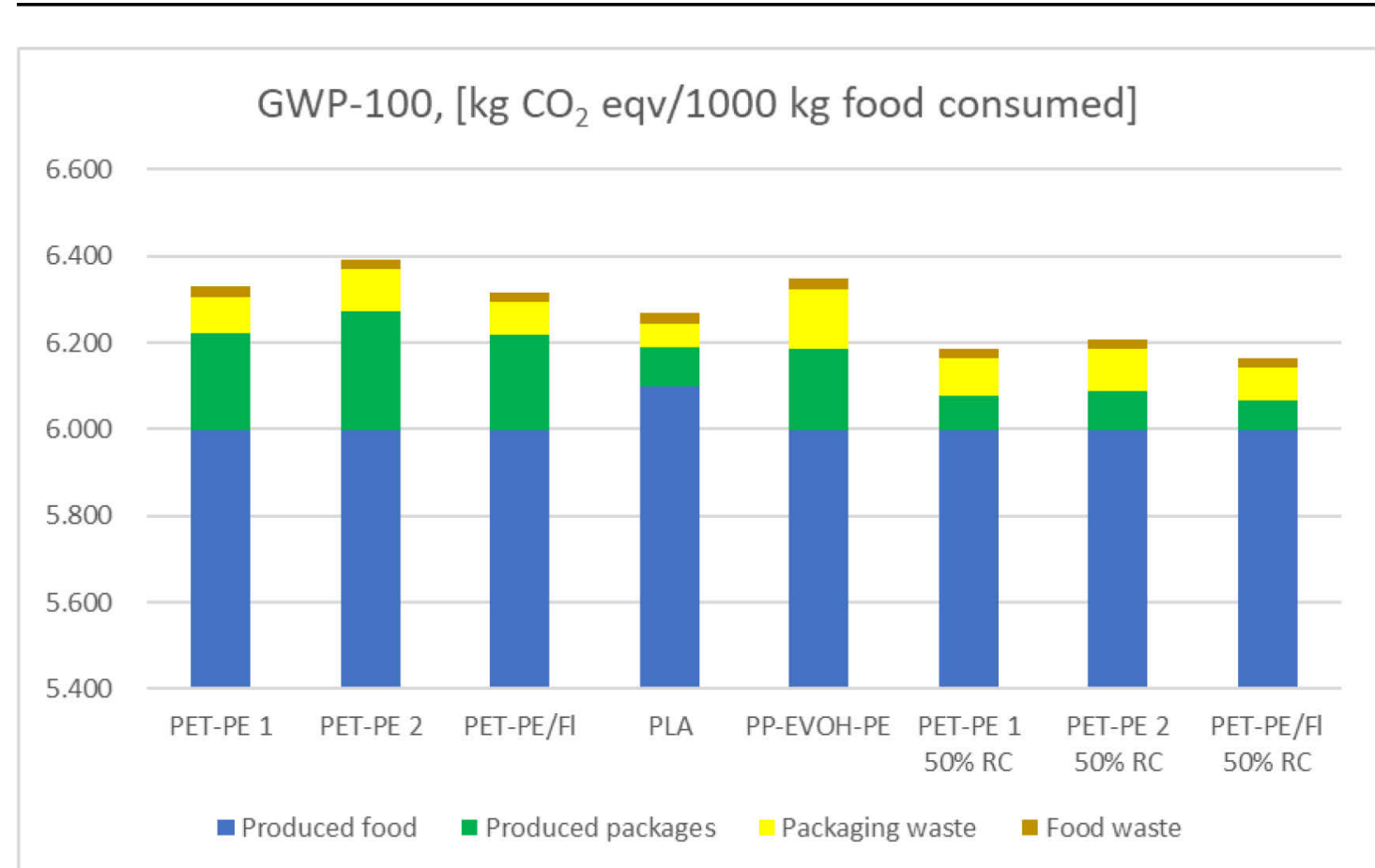

Figure $7 \quad$ Potential for greenhouse gas emissions over 100 years, as expressed for eight packaging types for poultry meat

The performance indicators of the poultry meat packages are listed in table 3. Overall they are fairly similar. The PET-trays with recycled content have a slightly reduced environmental impact in comparison to the other trays. The only package that is currently recyclable is the PP based tray. Perhaps the PET trays will become recyclable in the future and if so, they might even become circular recyclable, once the required recycling technologies have been developed. The PLA trays are currently also not recycled, but could be recycled either via organic waste or via a separate mechanical route. This is, however, currently not the case.

None of the poultry meat packages are able to prevent the formation of litter and hence this is completely in the hands of the civilians and their discarding behaviour. Although one can argue that meat packages are used in the kitchen and are less likely to be littered, one can also not exclude this behaviour. 
Table $3 \quad$ Overview of all the performance indicators for the poultry packages. RI is recycling indicator, CRI is circular recycling indicator and LPI is litter prevention indicator.

\begin{tabular}{|c|c|c|c|c|c|c|c|}
\hline Code & $\begin{array}{c}\text { Plastic - } \\
\text { product } \\
\text { ratio }\end{array}$ & $\begin{array}{l}\text { Relative } \\
\text { GWP-100 }\end{array}$ & BC packer & BC retailer & $\mathbf{R I}$ & CRI & LPI \\
\hline PET-PE 1 & $4 \%$ & $100 \%$ & 0 & 0 & $0 / 70 \%$ * & $0 / 70 \%{ }^{*}$ & $79 \%$ \\
\hline PET-PE 1 & & & 0 & & & & \\
\hline PET-PE 2 & & & 0 & & & & \\
\hline $50 \% \mathrm{RC}$ & $5 \%$ & $98 \%$ & & 0 & $0 / 80 \%{ }^{*}$ & $0 / 80 \%{ }^{*}$ & $77 \%$ \\
\hline PET-PE/FI & $4 \%$ & $100 \%$ & 0 & 0 & $0 / 87 \%$ * & $0 / 87 \%{ }^{*}$ & $76 \%$ \\
\hline PET-PE/FI & & & 0 & & & & \\
\hline PP-EVOH-PE & $6 \%$ & $100 \%$ & 0 & 0 & $79 \%$ & $0 \%$ & $76 \%$ \\
\hline
\end{tabular}

*: the recycling technology for PET-trays is not operational yet

!: the PLA meat trays are industrially compostable and could be circularly recycled via the organic waste route, alternatively a separate recycling system could be established.

$\mathrm{BC}=$ Business Costs. The qualitative substantiation is given in Annex 4.

To progress with poultry meat trays towards a more circular recycling system, the meat packaging industries are highly dependent on the investments in development work by the recycling industries. In case they manage to develop a circular recycling process for PET trays, then the meat packaging industries will greatly benefit from that development.

Up to that moment, the meat packaging industries can only take limited steps to make their packages more suitable for a circular economy. They can reduce the weight of the non-PET parts of the packages (labels, absorbers, etc.) and they can increase the recycled content of their PET trays. This recycled material will have to originate from PET bottles, since a recycling technology for PET trays is still lacking.

In case a poultry company focuses on reducing food loss and environmental impacts of the poultry meat - packaging system than it will probably choose for a PET-PE tray with an optimal logistical system and retail ordering system. In case a poultry company wants to use a recyclable package, within the constraints of the current recycling system, then it will probably opt for PP-EVOH-PE tray. In case a poultry company wants to contribute to the circular economy, then it will continue with PET-PE trays or PET-PE/FI trays and support all initiative to develop recycling technologies for PET trays.

\section{A new Norwegian approach}

After this study was conducted and just prior to publication of this report, a Norwegian study was released in which they replaced the PET-PE trays by thicker HDPE trays. These alternative trays are recyclable with $\mathrm{PE}$ bottles and might form an alternative solution for the currently still non-recyclable PET-PE trays. These HDPE trays need the same top-film (BOPET-PE-EVOH-PE) as the PET-PE trays. The gas permeability of the HDPE based was slightly higher than of the PET-PE trays, but the shelf life of chicken breast fillets packaged inside the trays was very comparable. Several subtle differences were noticed between the trays in relation to microbiological growth, drip loss formation and offodours. The packages were tested not only with high oxygen atmospheres as is common in the Netherlands, but also with high carbon dioxide atmosphere as is common in Norway [Pettersen et al., 2020]. 


\section{Discussion}

\subsection{Can we live without plastic packaging in a modern society?}

Several individuals have tried to live without plastics. Some of them have documented their attempts on social media and in newspapers [Koetsenruijter 2019; Meulen van der 2013]. In general, these individuals were indeed able to reduce their consumption of plastics largely, but it also meant that they needed to make substantial changes to their life style. They were forced to change their habits, shopping routines and skip several products. For most fruit and vegetable products, it often implied to shop for loose products (that are often organic). For the smaller products, such as soft fruits (red currants, strawberries, raspberries, blueberries etc.) this implied shopping in markets instead of supermarkets, and in some cases bringing self-owned food containers and asking the market salesman to put the products in these.

In case of meat products it implied going to butcher stores instead of supermarkets and asking for paper wrapping or taking self-owned plastic containers to the store and asking the butcher to pack it in these containers.

For processed dried food items it meant avoiding supermarkets and going to specialty stores and asking for paper bags. For dairy products, they visited farm outlets with glass bottles or sold their milk / yoghurt at organic stores in glass returnable bottles.

For some personal care products, it meant to no longer use shower gel \& shampoo but soap bars instead. To avoid deodorants they advise to prepare at home formulations each week and they posted instructions.

These examples show that individuals can live in a modern society and reduce their use of plastic packages largely. But they will have to change their habits and daily routines. They will have to shop in multiple stores instead of one supermarket. Furthermore, they will have to shop more frequently, typically 2-3 times a week instead off once a week. And finally, more food and personal care products will have to be prepared at home. For those individuals that have sufficient time and knowledge, this is a feasible solution.

With most civilians running a hectic life this is, however, not a realistic lifestyle. Especially on the level of the whole society, it is unlikely that civilians will change their behaviour and life styles en-masse. Although it is possible to reduce the use of plastic packages in all households to some extent, packages cannot be removed away from our lives, not for multiple consumer articles and not for fresh produce packages [White \& Lockyer, 2020]. A complete swap from plastic packages to glass, metal and paper \& board will create very large additional carbon dioxide emissions due to the much larger packaging weights [Brandt \& Pilz, 2011; Voulvoulis et al., 2020]. This implies that on the level of the whole society a more subtle approach has to be advised: to reduce the use of plastic packages where possible without creating larger environmental side-effects. This boils down to addressing those plastic packages that are truly superfluous and have no protective function. The second more difficult question is then who will decide what is superfluous among the millions of packed consumer articles and which policy is most effective (covenants, bans, $\mathrm{CO}_{2}$-taxes, virgin plastic taxes?). Irrespective of the policies that will be chosen in the future by governments, it is going to be an obligation for packaging developers to reduce the use of plastic packages to justifiable and sensible levels.

\subsection{Sustainable packages, food industries in the lead}

Roughly two third of the packages are used for food-products. Furthermore, increasing shares of nonfood consumer articles are nowadays produced in Asia, where there is less control over the packaging designs. This put the European food industry in the lead towards the use of more sustainable packages in Europe.

But simultaneously, the European food industry is restrained by the options that packaging industries and the recycling industries offer and the expectations of consumers and retailers. Attempts to 
redesign-for-recycling often result in dilemmas. Proposals for redesigned packages that are more compatible with the sorting and recycling industries, regularly conflict with the primary packaging functions.

\section{Dilemmas in design-for-recycling}

The dilemmas that were apparent in the snack tomato and fresh poultry meat case are:

1. Optical transparency of the package (hence sales) versus recyclability.

2. Dependence of the fresh food industry of other stakeholders (EPR scheme operators, sorters and recyclers) in reaching their sustainability goals; especially the development of a technology to recycle PET trays.

3. Perception versus recyclability. The so-called regrettable replacements. Alternative packaging formats with a positive consumer perception and which appear to have a lower environmental impact, but in fact have a higher environmental impact (other materials such as glass, metals, paper \& board). An example is the paper cup shaker for the snack tomatoes.

4. Redesign based on the possibilities that current recycling technologies offer, or wait for future recycling technologies that can handle the current packages? Should a meat packer redesign its PET-PE trays to PP-EVOH-PE, or rather wait for the development of recycling technologies for PET trays? This dilemma is also encountered with food companies that currently use PS packages; should they redesign to PET / PP based packages or wait for pyrolysis technologies to become available?

In other packaging markets also other dilemmas are encountered:

5. Convenience versus recyclability. Many consumers and retailers / outlets expect the package to offer sufficient convenience for the end-user (spoons, straws, easy opening, reclose-able strips, spray guns, hand pumps, etc.). In most cases the added convenience components hamper the recycling and hence they should preferably be phased out.

6. Marketing versus recyclability. Sales promoting prints on the package, that are difficult to remove and causes the recycled plastic to be more contaminated. Examples are: full body sleeves that hamper NIR sorting, or metallic prints on packages.

7. Food waste versus recyclability. Extended shelf-life for products that rely on non-recyclable packaging types and have become common but are not strictly necessary when the food companies would change their logistics and consumers change their shopping behaviour. For example: Pre-baked bread buns in non-recyclable PA-PE or PET-PE laminated flexible packages with a 3 months shelf life versus the same product in a recyclable PE bag with only 1 week of shelf life.

8. Complicated food safety issues versus the use of recycled materials. Although recycled materials have in general a positive consumer perception, they can also result in additional food safety issues that have to be controlled and managed. This not only complicates the tasks of the food industry, it also makes them more vulnerable for safety issues that are beyond their normal span of control. Recycled paper fibres are the best known examples. The material has a positive consumer perception, but possesses various food safety risks that are difficult to evaluate [Pivnenko et al. 2015; Koster et al., 2020].

These dilemmas can only be resolved by the active participation of all stakeholders and especially the consumers. Progress in the circular recycling of packages does not only depend on technical barriers that can be resolved with R\&D work, it will also require a change in consumer behaviour. Progress towards a more circular economy for plastic packages also requires consumers to choose for packages without convenience options, with less graphics and less optical transparency.

Most dilemmas are tenacious and concerted actions of all stakeholders will be required to resolve them. For instance, new recycling technologies for PET trays are expensive to develop and it is unlikely that a recycling industry is able to succeed to do so, without substantial support for the other stakeholders. Similarly, in case one hand soap producer continues to market hand pumps, it is unlikely that the competitors will stop offering those.

\section{Opposing trends}

Although multiple stakeholders attempt to reduce the amount of packaging materials used, in the food market we see three trends that oppose this reduction. First of all, the size of households reduces 
annually and since smaller households use more plastic packaging material per amount of product consumed, the total consumption of plastic packages is growing. Secondly, there is a trend that is particularly strong in the market for fresh vegetable produce to bundle loose vegetables into 'meal concepts'. This helps consumers to buy the right vegetables for a chosen meal and apparently there is a market for these concepts. Nevertheless the final result is that vegetables that are normally sold unpacked loose are becoming packaged in bundles and more packaging materials are used again. Finally, during the COVID-19 pandemic more fresh food products were packed again for hygiene reasons.

\section{Beware of regrettable replacements}

In the case of the snack tomatoes, the paper cup with the plastic hood in particular could be regarded as a 'regrettable replacement'. This is an existing packaging type from the fast food industry that is converted for use as snack tomato package. Overall it will have a positive consumer perception since it is predominantly composed of paper fibres. But this package is not targeted for in any separate collection system; not in separately collected paper and board and neither in the separately collected lightweight packaging waste (LWP, locally known as PMD). It acts as a contaminant in the recycling of paper. Furthermore it is a non-targeted material in the LWP collection, sorting and recycling. Although in theory it could be recycled with beverage cartons, this has not been proven yet. Additionally, multiple incumbents (sorting facilities, recycling facilities, EPR scheme operators) have responded defensively towards non-compliant packaging types, in the past (see for example the case with the PLA trays below). These responses form additional risks for the food companies that seek to use packages that are made of less plastic material.

In the case of the meat trays, several stakeholders have framed the PLA trays as a regrettable replacement. This is however unfair, since there is no alternative that is recycled; PET-trays are currently also not recycled and PP-EVOH-PE trays might contaminate the recycled PP product. Furthermore, all the claims that the PLA trays would contaminate the organic waste were not substantiated with measured facts; almost exclusively fossil based plastics were found in organic waste [Zee vd \& Molenveld, 2020].

\subsection{Informed decisions need reliable data}

There is a clear need for reliable data on food wastage in the supply chain and at home to make informed and widely supported decisions on the designs of integrally more sustainable food packages. This data is either competition sensitive business intelligence and often not publicly available, or difficult to measure in a reliable manner. There is no clear case description available of a conventional package and an alternative, improved package that includes all the food waste loss data in the distribution chain and at the consumers at home. This lack of reliable data hampers the further development food packages that are objectively more sustainable. It inhibits food and packaging companies to present their contributions to minimise the environmental impacts of supply chains and get recognition for their efforts to do so. Furthermore, due to this lack of reliable data on packagingrelated food wastage, NGO's can continue to proclaim that packages are superfluous, preferably need to be abolished, and at least need to be made recyclable.

Although the demand to make packages recyclable appears to be absolutely justifiable and morally correct, a closer inspection reveals that the road towards better recyclable packages is paved with dilemmas (section 5.2). Some of these dilemmas can be resolved by the food industries and their suppliers themselves, most however can only be resolved by the active involvement of all stakeholders. 


\subsection{There is no single answer to all environmental concerns}

In the unlikely case that we would have gathered all data on packaging-related food-wastage and understood its role completely and if we would have resolved the redesign dilemmas and only would have had recyclable packages, then packages would still contribute to plastic soup. The root-causes of littering and plastic soup formation lie in human behaviour and poor legislation (in most countries the export of waste to countries without waste treatment facilities is allowed and even officially registered as 'recycled' $)^{4}$. Although collection systems can limit the leakage of plastics to the environment, it will never prevent littering completely. Therefore, packaging will remain a focal point of discussions on the environmental impact of modern urbanised societies. It is impossible for food companies to prevent that their packages will be littered by citizens. To mitigate the negative consequences of packages being littered, these should be biodegradable. Paper and board based systems are often suggested as biodegradable alternative. But in order to obtain the required technical performance, plastic liners and coatings often need to be used, thereby hampering both full degradation and recyclability. Such alternatives would actually be a regrettable replacements. Alternatively, biodegradable plastics could be used. Then they need to be price-competitive, offer sufficient protection, degrade sufficiently fast in the environments where they are likely to be littered and finally they shouldn't interfere with existing recycling systems. That is a long and challenging list of requirements. Hence, it is no surprise that packages that tick all the boxes (cheap, sufficient protective, recyclable, circular recyclable and degradable once littered) haven't been developed yet. This also implies that food companies have to make strategic choices with respect to the sustainability themes they want to pursue: minimising food waste, minimising environmental impacts of the overall food-packaging system, recyclable, circular or littering-proof. Each strategy will result in different food packages. If multiple goals are chosen, the outcome is by definition a compromise. E.g.: a circular recyclable package will neither have the lowest environmental impact nor will be optimally littering-proof.

\footnotetext{
${ }^{4}$ Several European countries have announced laws to forbid those exports. Additionally the Basel convention has been adjusted accordingly from January $1^{\text {st }} 2021$ on, see:

http://www.basel.int/Implementation/Plasticwaste/PlasticWasteAmendments/Overview/tabid/8426/Default.aspx
} 


\section{Conclusions}

The quest for more circular recyclable plastic packages is impeded by multiple issues and dilemmas. There are no simple packaging solutions for fresh food companies that are simultaneously circular recyclable and inflict the lowest environmental impact for the complete value chains of products and packages. This implies that food companies have to make choices; to either pursue a circular recyclable packaging system or to reduce the environmental impact as much as possible.

On top of that, the use of plastic packages can result in littering and the generation of plastic soup. Although collection systems for plastic waste can reduce littering and hence plastic soup, they cannot prevent it completely, since producers and governments have no control over the discarding behaviour of individual citizens. Therefore, there is no final answer to the environmental issues with packaging; a package is required in a modern urban society where production and consumption are separated, but simultaneously this package-product-combination causes environmental concerns. Food companies and packaging engineers respond to these concerns by modifying their supply chains and packaging designs. Since the societal focus on these environmental concern shifts gradually in time, also the developed solutions that attempt to answer these concerns, will change gradually in time.

Progress towards a more circular recycling system for fresh food packages is currently hampered by the absence of a recycling system for 'non-bottle PET' (PET trays and related packages). This was apparent in both studied cases of snack tomatoes and poultry meat products. The development of such a recycling technology requires R\&D efforts and can only become a technological and economic success in case the contributing food companies are willing to modify their packaging designs. Additionally, policies of EPR scheme operators and governments can assist in the development of this technology and concomitant design-guidelines. In short, progress can be made and the packaging system for fresh food products can be made more circular in the coming years, but it requires large efforts of all stakeholders, that need to be well-orchestrated to be effective. 


\section{Literature}

Abejón, R., Bala, A., Vázquez-Rowe, I., Aldaco, R., Fullana-i-Palmer, P. 2020. When plastic packaging should be preferred: Life cycle analysis of packages for fruit and vegetable distribution in the Spanish peninsular market. Resourc. Conserv. Recycl. 155, 104666; https://doi.org/10.1016/j.resconrec.2019.104666

Afvalfonds 2020, website, accessed on January $15^{\text {th }} 2020$, https://afvalfondsverpakkingen.nl/en/packaging-waste-management-contribution

Anonymus 2020. Wasbaar zakje, komkommer in een pakje. Food Personality February p18-21.

Bellarby, J., Tirado, R., Leip, A., Weiss, F., Lesschen, J.P., Smith, P. 2013. Livestock greenhouse gas emissions and mitigation potential in Europe. Global change Biology. 19, 3-18. Doi: 10.1111/j.1365-2486.2012.02786.x.

Brandt B, Pilz H. 2011. The impact of plastic packaging on life cycle energy consumption and greenhouse gas emissions in Europe. Denkstatt: Vienna.

Brouwer, M.T., Thoden van Velzen, E.U., Augustinus. A., Soethoudt, H., DeMeester ,S., Ragaert, K., 2018. Predictive model for the Dutch post-consumer plastic packaging recycling system and implications for the circular economy. Waste manage. 71, 62-85. DOI: 10.1016/j.wasman.2017.10.034.

Brouwer MT, Picuno C, Thoden van Velzen EU, Kuchta K, De Meester S, Ragaert K, 2019. The impact of collection portfolio expansion on key performance indicators of the Dutch recycling system for Post-Consumer Plastic Packaging Waste, a comparison between 2014 and 2017. Waste Management. 100: 112-121. https://doi.org/10.1016/j.wasman.2019.09.012

Civancik-Uslu D, Puig R, Hauschild M, Fullana-i-Palmer P. 2019. Life cycle assessment of carrier bags and development of a littering indicator. Sci. Total Environm. 685: 621-630.

Crippa, M., De Wilde, B., Koopmans, R., Leyssens, J., Muncke, J., Ritschkoff A-C., Van Doorsselaer, K., Velis, C. \& Wagner, M. 2019. A circular economy for plastics - Insights from research and innovation to inform policy and funding decisions, (M. De Smet \& M. Linder, Eds.). European Commission, Brussels, Belgium.

COOP. 2017 COOP introduceert biologisch afbreekbare vleesverpakking. Press release: https://www.coop.nl/over-coop/biologisch-afbreekbare-vleesverpakkingen

Dahlbo, H., Poliakova, V., Mylläri, V., Sahimaa, O., Anderson, R., 2018. Recycling potential of postconsumer plastic packaging waste in Finland. Waste Manage. 71, 52-60. https://doi.org/10.1016/j.wasman.2017.10.033

European Union 1992. Packaging and packaging waste directive 64/92. Official Journal of the European Union L 365/10.

European Union 2008. Waste framework directive 2008/98. Official Journal of the European Union L $312 / 3$.

European Commission. 2018. A European strategy for Plastics in a circular economy.

European Union 2019. Directive on the reduction of the impact of certain plastic products on the environment. Official Journal of the European Union L155/1.

European Commission, 2015. Closing the loop - An EU action plan for the circular economy, EC Communication 2015 614, Brussels.

Ellen Macarthur Foundation. 2016. The new plastic economy. https://www.ellenmacarthurfoundation.org/publications/the-new-plastics-economy-rethinking-thefuture-of-plastics

Ellen Macarthur Foundation. 2019. The new plastic economy global commitment report.

Green Alliance, 2020. Plastic Promises, what the grocery store is really doing about packaging. Green Alliance: London.

Hahladakis, J.N., Purnell, P., Iacovidou, E., Velis, C., Atseyinku, M., 2018. Post-consumer plastic packaging waste in England: Assessing the yield of multiple collection-recycling schemes. Waste Manage. 75, 149-59. Doi: 10.1016/j.wasman.2018.02.009.

Halopack website: www.halopack.eu (accessed June $12^{\text {th }} 2020$ ).

KIDV website: https://www.kidv.nl/9163/kidv-recyclecheck.html \{accessed 2020 Jan $15^{\text {th }}$ \} 
Kirchherr J., Reike D. Hekkert M. 2017. Conceptualizing the circular economy: an analysis of 114 definitions. Resourc. Conserv. Recycl. 127: 221-232.

https://doi.org/10.1016/j.resconrec.2017.09.005

Koetsenruijter L. 2019. Kun je leven zonder plastic? Journal article. Volkskrant. https://www.volkskrant.nl/columns-opinie/kun-je-leven-zonder-plastic-v-vlogger-lisakoetsenruijter-deed-een-poging b2964220/?referer=https\%3A\%2F\%2Fwww.google.com\%2F

Koster S. et al. 2020. Mineral oil hydrocarbons in foods: is the data reliable? Food Additives and Contaminants A. 37(1): 69-83.

Ipsos Mori 2018. website. https://www.ipsos.com/ipsos-mori/en-uk/public-concern-about-plastic-andpackaging-waste-not-backed-willingness-act \{accessed 2020 Jan 15 \}

Lebreton L. et al. 2018. Evidence that the great pacific garbage patch is rapidly accumulating plastic. Sci. Rep. 8, 4666.

MacLeod, M., Gerber, P., Mottet, A., Tempio, G., Falcucci, A., Opio, C., Vellinga, T., Henderson, B. \& Steinfeld, H. 2013. Greenhouse gas emissions from pig and chicken supply chains - A global life cycle assessment. Food and Agriculture Organization of the United Nations (FAO), Rome.

Natural branding, 2020. https://www.natureandmore.com/en/natural-branding/what-is-naturalbranding.

Pettersen MK, Grøvlen MS, Evje N, Radusin T. 2020. Recyclable mono materials for packaging of fresh chicken fillets: New design for recycling in circular economy. Packag. Techno. Sci. 1-14; DOI: $10.1002 /$ pts. 2527 .

Pivnenko K. et al. 2015. Waste paper for recycling: Overview and identification of potentially critical substances. Waste Management 45: 134-142 http://dx.doi.org/10.1016/j.wasman.2015.02.028

Plastic Pact. Letter of the under-minister of environmental affairs of the Netherlands to the parliament of February $20^{\text {th }} 2019$, https://www.rijksoverheid.nl/documenten/kamerstukken/2019/02/20/plastic-pact-nl [Accessed 2020 January 21st ]

PRE 2020. Website. https://www.plasticsrecyclers.eu/glossary \{accessed 2020 Jan $15^{\text {th }}$ \}

Robertson G. 2013. Food packaging principles and practise. CRC press: Boca Raton.

Skene KR. 2018. Circles, spirals, pyramids and cubes: why the circular economy cannot work. Sustain Sci. 13: 479-492; https://doi.org/10.1007/s11625-017-0443-3

Teuten EL, et al. 2009. Transport and release of chemicals from plastics to the environment and to wildlife. Philos. Trans. R. Soc. B: Biol Sci.364, 2027-2045.

Theurl MC, Haberl H, Erb KH, Lindenthal T. 2014. Contrasted greenhouse gas emissions from local versus long-range tomato production. Agron. Sustain. Dev. (2014) 34:593-602.

Thoden van Velzen EU, Linnemann AR. 2008. Modified atmosphere packaging of fresh meats - sudden partial adaptation caused an increase in sustainability of Dutch supply chains of fresh meats Packaging Technology and Science. 21, 37-46, DOI: 10.1002/pts.776 .

Thoden van Velzen EU. 2011. Natuurlijk verpakt. WFBR report 1142, January $5^{\text {th }} 2011$.

Thoden van Velzen EU. 2017. Recyclingopties voor PET schalen. WFBR report 1761 , July $20^{\text {th }} 2017$, http://library.wur.nl/WebQuery/wurpubs/fulltext/419818

Turner DA, Williams ID, Kemp S. 2015. Greenhouse gas emission factors for recycling of sourcesegregated waste materials. Resources, Conservation and Recycling 105: 186-197.

VA (Vereniging Afvalbedrijven). 2018. Press release: Bioplastics: welke wel/niet?. https://www.verenigingafvalbedrijven.nl/nieuws/nieuwsbericht/bioplastics-welke-welniet.html

Eygen van, E., Laner, D., Fellner, J., 2018. Circular economy of plastic packaging: Current practice and perspectives in Austria. Waste Manage. 72, 55-64. https://doi.org/10.1016/j.wasman.2017.11.040

Meulen van der M. 2013. Het kan wel. Website:https://www.hetkanwel.nl/2013/07/29/leven-zonderplastic-39-tips/

Vouvoulis N, Kirkman R, Giakoumis T, Metivier P, Kyle C, Midgley P. 2020. Plastic packages versus the alternatives, examining material evidence, the carbon fingerprint. Imperial college london; London; https://cdn.ca.emap.com/wp-content/uploads/sites/6/2020/07/Veolia-PlasticWhitepaper.pdf

White A, Lockyer S. 2020. Removing plastic packaging from fresh produce - what's the impact? Nutrition Bulletin. 45: 35-50. DOI: 10.1111/nbu.12420.

Williams H, Wikström F. 2011. Environmental impact of packaging and food losses in a life cycle perspective: a comparative analysis of five food items. Journal of Cleaner Production 19: 43-48. 
Wikström F, Williams H, Verghese K, Clune S. 2014. The influence of packaging attributes on consumer behaviour in food-packaging life cycle assessment studies - a neglected topic. Journal of Cleaner Production 73: 100-108.

Zee van de M, Molenveld K. 2020. The fate of (compostable) plastic products in a full scale industrial organic waste treatment facility, Wageningen, WFBR report 2020, https://doi.org/10.18174/514397 


\section{Abbreviations}

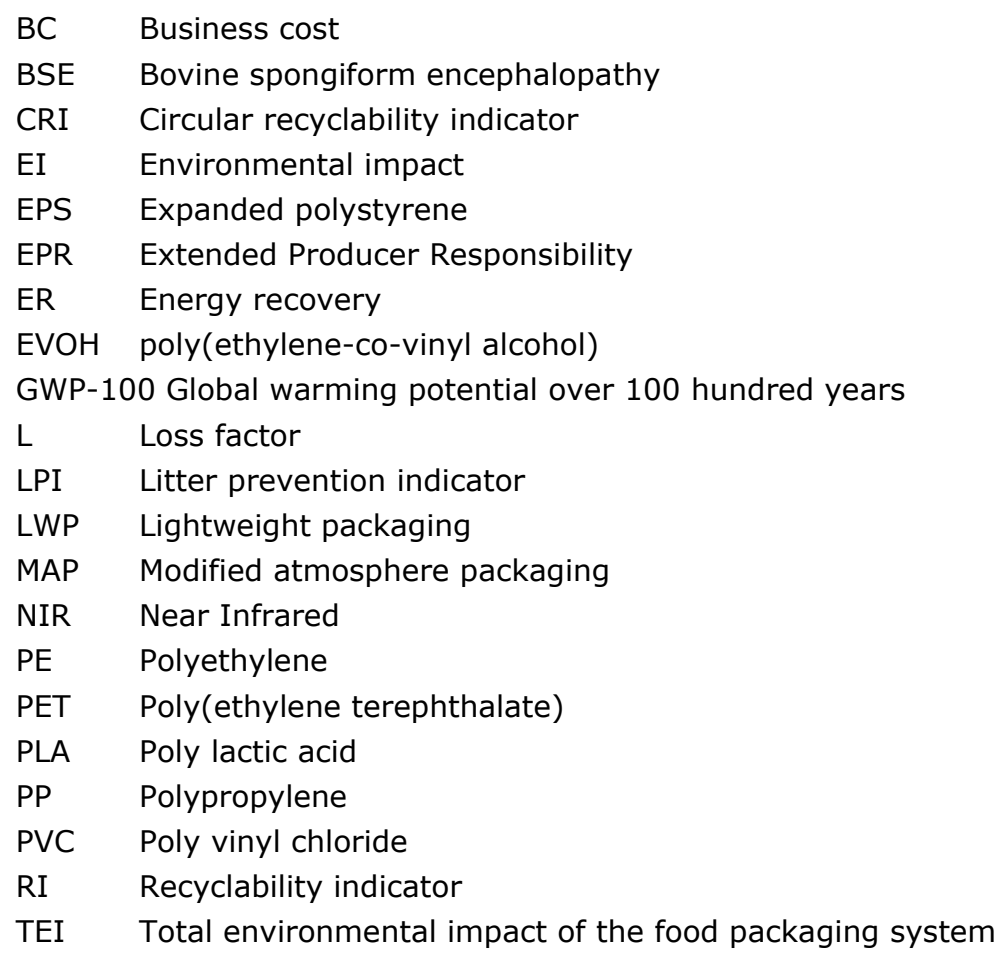




\section{Annex 1 Research data}

\subsection{Material composition of the studied packages}

Material composition of the studied packages for the snack tomatoes.

\begin{tabular}{|c|c|c|c|c|}
\hline Code & Components & $\begin{array}{l}\text { Total weight, } \\
\text { [g/unit] }\end{array}$ & $\begin{array}{l}\text { Intended product } \\
\text { weight, [g/unit] }\end{array}$ & $\begin{array}{l}\text { Outer dimensions, } \\
\text { [cm] }\end{array}$ \\
\hline S1 & $\begin{array}{l}\text { PET shaker } 9.18 \mathrm{~g} \\
\text { PET cap } 4.33 \mathrm{~g} \\
\text { PE Side label } 0.20 \mathrm{~g}\end{array}$ & 13.71 & 250 & $\begin{array}{l}\mathrm{H} 12.5 \\
\varnothing 9.3\end{array}$ \\
\hline $\mathrm{S} 2$ & $\begin{array}{l}\text { PET shaker } 11.96 \mathrm{~g} \\
\text { PET cap } 5.40 \mathrm{~g} \\
\text { Paper barcode label } 0.10 \mathrm{~g}\end{array}$ & 17.46 & 250 & $\begin{array}{l}\mathrm{H} 13.5 \\
\varnothing 9.3\end{array}$ \\
\hline s3 & $\begin{array}{l}\text { PP shaker } 7.57 \mathrm{~g} \\
\text { PET cap } 3.91 \mathrm{~g} \\
\text { PP front label } 0.18 \mathrm{~g} \\
\text { PP back label } 0.11 \mathrm{~g}\end{array}$ & 11.77 & 250 & $\begin{array}{l}\text { H } 12.5 \\
\varnothing 9.5\end{array}$ \\
\hline B1 & $\begin{array}{l}\text { PP bucket } 25.10 \mathrm{~g} \\
\text { PET cap } 5.53 \mathrm{~g} \\
\text { PP cap label } 0.18 \mathrm{~g} \\
\text { PP strap } 1.29 \mathrm{~g} \\
\text { Paper barcode label } 0.20 \mathrm{~g}\end{array}$ & 32.80 & 500 & $\begin{array}{l}\mathrm{H} 13.6 \\
\varnothing 11.5\end{array}$ \\
\hline B2 & $\begin{array}{l}\text { PP bucket } 25.50 \mathrm{~g} \\
\text { PET cap } 5.86 \mathrm{~g} \\
\text { PP cap label } 0.17 \mathrm{~g} \\
\text { PP strap } 1.20 \mathrm{~g} \\
\text { Paper barcode label } 0.08 \mathrm{~g}\end{array}$ & 32.81 & 500 & $\begin{array}{l}\mathrm{H} 13.5 \\
\varnothing 11.5\end{array}$ \\
\hline CB1 & $\begin{array}{l}\text { Carton box } 16.13 \mathrm{~g} \\
\text { Paper label } 0.20 \mathrm{~g}\end{array}$ & 16.33 & 350 & $\begin{array}{l}\text { H } 13.5 \\
\text { L } 7.9 \times \text { W } 7.9\end{array}$ \\
\hline CB2 & $\begin{array}{l}\text { Carton box } 13.10 \mathrm{~g} \\
\text { PLA window } 1.75 \mathrm{~g} \\
\text { Paper label } 0.20 \mathrm{~g}\end{array}$ & 15.05 & 350 & $\begin{array}{l}\text { H } 13.5 \\
\text { L } 7.9 \times \text { W } 7.9\end{array}$ \\
\hline CB3 & $\begin{array}{l}\text { Carton box } 11.13 \mathrm{~g} \\
\text { PLA window } 1.02 \mathrm{~g} \\
\text { Paper label } 0.20 \mathrm{~g}\end{array}$ & 12.35 & 175 & $\begin{array}{l}\text { H } 12 \\
\text { L } 5.9 \times \text { W } 5.9\end{array}$ \\
\hline cS1 & $\begin{array}{l}\text { Carton cup } 9.0 \mathrm{~g} \\
\text { PET cap } 4.31 \mathrm{~g} \\
\text { PE cup coating } 0.20 \mathrm{~g}\end{array}$ & 13.51 & 275 & $\begin{array}{l}\text { H } 13.1 \\
\varnothing 9.3\end{array}$ \\
\hline SP1 & PP stand-up pouch & 4.27 & 500 & $\begin{array}{l}\mathrm{H} 20 \mathrm{~cm} \\
\mathrm{~W} 16 \mathrm{~cm}\end{array}$ \\
\hline
\end{tabular}


Material composition of the studied poultry meat packages.

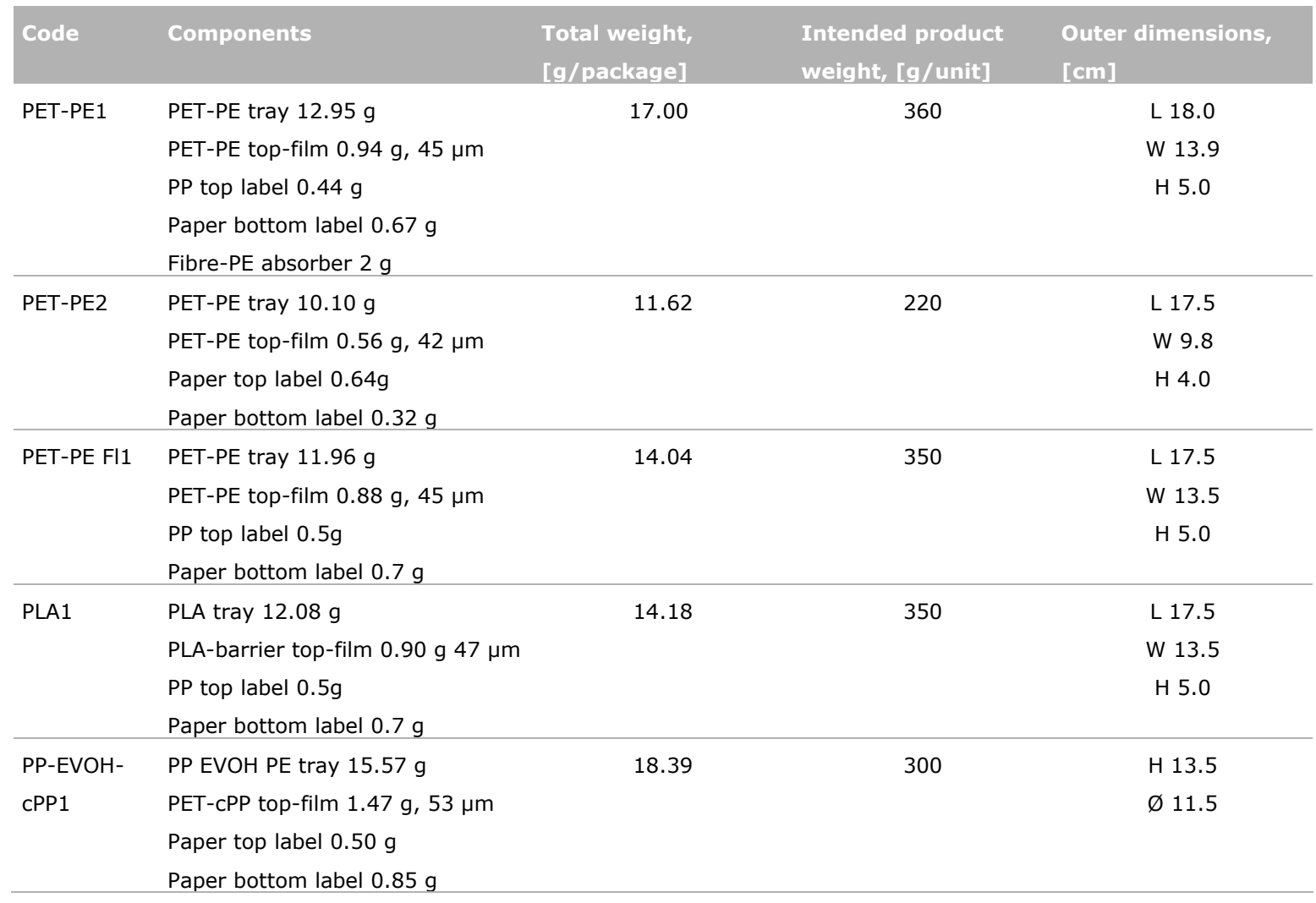

\subsection{Parameters for the calculation of the environmental impact}

Emission factors for food products

\begin{tabular}{lll} 
Food product & $\begin{array}{l}\text { Emission factor GWP-100, }\left[\mathrm{kg} \mathrm{CO}_{2}\right. \\
\text { eqv./ } \mathrm{kg} \text { food product }]\end{array}$ & Source \\
\hline Tomatoes, open field & 0.7 & Theurl et al. 2014 \\
\hline Tomatoes, greenhouse & 1.3 & Theurl et al. 2014 \\
\hline Poultry meat & 5.4 & MacLeod et al. 2013 \\
\hline Poultry meat & $3.7-6.9$ & Bellarby et al. 2013 \\
\hline
\end{tabular}


Emission factors for packaging production

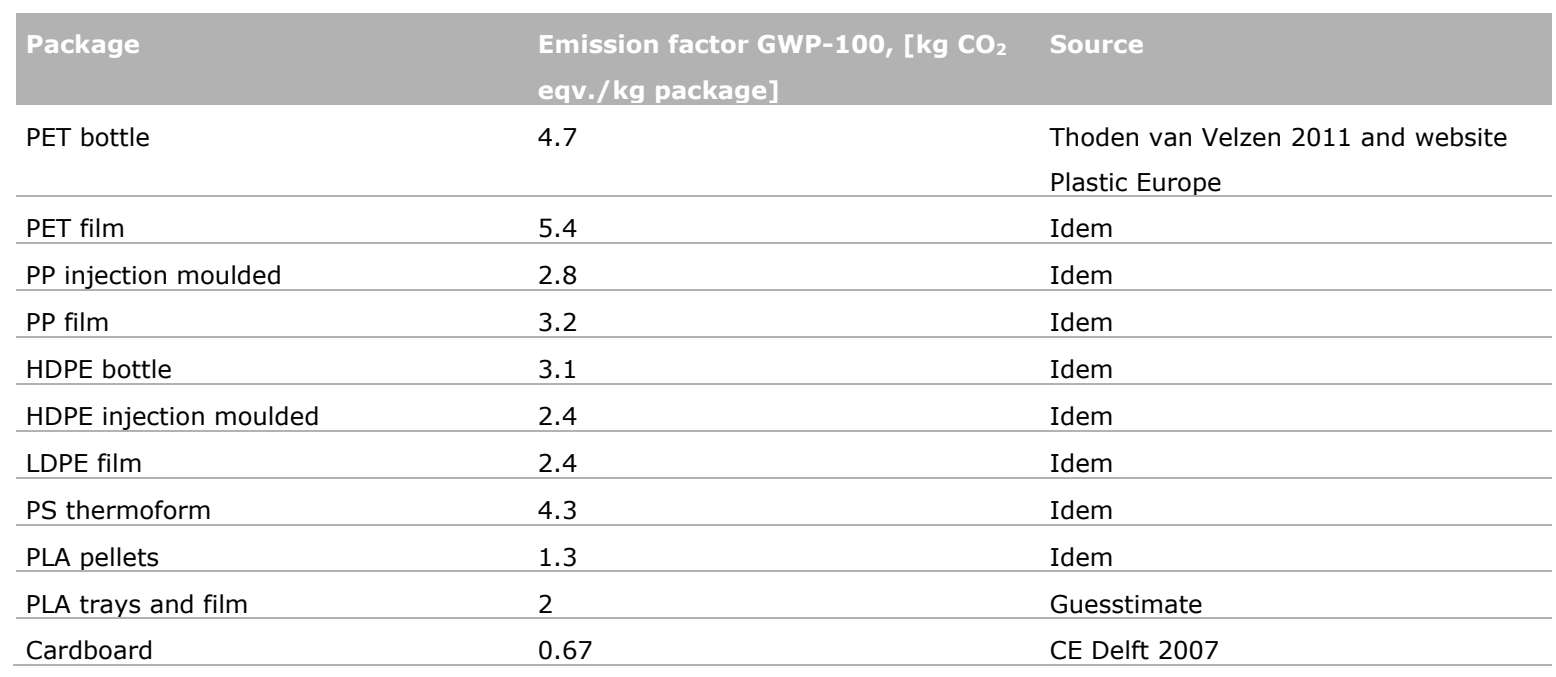

Emission factors for recycling plastic packages

\begin{tabular}{lll} 
Package & Emission factor $\mathrm{GWP-100,}\left[\mathrm{kg} \mathrm{CO}_{2}\right.$ & Source \\
& eqv./ kg package] & Wikstrom et al. 2014 \\
\hline Recycled PET & -2.4 & Turner et al. 2015 \\
\hline Recycled PET & -2.2 & Wikstrom et al. 2014 \\
\hline Recycled PP & -1.7 & Turner et al 2015 \\
\hline Recycled PP & -1.2 & Turner et al 2015 \\
\hline Recycled HDPE & -1.1 & Wikstrom et al. 2014 \\
\hline Recycled LDPE & -1.8 & Turner et al. 2015 \\
\hline Recycled Cardboard & -0.97 & Turner et al. 2015 \\
\hline
\end{tabular}

Emission factors for waste management packages

\begin{tabular}{lll} 
Package & $\begin{array}{l}\text { Emission factor } \mathrm{GWP-100,}\left[\mathrm{kg} \mathrm{CO}_{2}\right. \\
\text { eqV./ } \mathrm{kg} \text { package }]\end{array}$ & Source \\
\hline Incineration PET in NL with ER & $2.16-0.50=1.66$ & Thoden van Velzen 2011 \\
\hline Incineration PP in NL with ER & $3.14-0.96=2.18$ & Idem \\
\hline Incineration PE in NL with ER & $3.14-0.96=2.18$ & Idem \\
\hline Incineration PS in NL with ER & $3.38-1.01=2.37$ & Idem \\
\hline Incineration PLA in NL with ER & $1.83-0.59=1.24$ & Idem \\
\hline Incineration cardboard in NL with ER & $1.5-0.5=1.0$ & Guesstimate
\end{tabular}




\section{Annex 2 Interviewed incumbents}

Arno Dekkers

Arjan Hagoort

Paul Hendriks

Martine Onderdijk

Harold Rouweler
Storteboom-2sisters, Putten

Bliston packaging, Nijkerk

EOSTA, Waddinxveen

Storteboom-2sisters, Putten

Promessa, Deventer 


\section{Annex 3 Sensitivity analysis}

To probe the sensitivity of the calculated values for the global warming potential over 100 years for the packaged snack tomatoes, six scenario's with different initial parameters were also calculated. These results are listed in table A3.1. As can be observed, the production method for the snack tomatoes has the largest impact on the final results. All the other scenarios have a less than $13 \%$ influence on the final result.

\begin{tabular}{|c|c|c|c|}
\hline Scenario & Modelled difference & Changed parameters & $\begin{array}{l}\text { Total environmental } \\
\text { impact [ } \mathrm{kg} \mathrm{CO} 2 \text { eqv } / \mathrm{kg} \\
\text { food] and the relative } \\
\text { difference in brackets }\end{array}$ \\
\hline Reference, S1 & none & none & $1.926(0 \%)$ \\
\hline 1 & Open field production & $\begin{array}{l}\text { Emission factor } \\
\text { production tomatoes to } \\
0.7 \mathrm{~kg} \mathrm{CO} \text { eqv. } / \mathrm{kg}\end{array}$ & $1.250(35 \%)$ \\
\hline 2 & PET is recycled & EoL-factors & $1.847(4 \%)$ \\
\hline 3 & $\begin{array}{l}\text { Lower food waste at } \\
\text { consumer }\end{array}$ & $\begin{array}{l}\text { Food waste at consumer } \\
4 \%\end{array}$ & $1.840(4 \%)$ \\
\hline 4 & $\begin{array}{l}\text { Higher food waste at } \\
\text { consumer }\end{array}$ & $\begin{array}{l}\text { Food waste at consumer } \\
12 \%\end{array}$ & $2.034(6 \%)$ \\
\hline 5 & $\begin{array}{l}\text { PET is recycled and the EoL } \\
\text { is maximised }\end{array}$ & $\begin{array}{l}\text { EoL factors to } 90 \% \\
\text { recycling }\end{array}$ & $1.704(12 \%)$ \\
\hline
\end{tabular}




\section{Annex 4 Qualitative substantiation of the business costs}

\section{Snack tomatoes}

The business costs for the packing company was raised when the packages themselves were more expensive and in case the packaging process could not be performed with machines but had to be done manually. This resulted in slightly higher business costs for the carton-based packages. The PP-based stand-up pouches are cheaper than any rigid package and hence this is slightly cheaper for the packaging company.

The business costs for the retailer was raised when the EPR fees for the packaging type (normalised per product weight) were higher, as was the case for the plastic bucket type packages, when the packages cannot be stacked as is the case for the S2 and when less sales can be expected. The latter is the case for the carton-based packages. Two packaging types were relatively light-weighted (S3 and SP1) and consequently had slightly lower retail costs.

\section{Poultry meat products}

The PLA trays and the concomitant top-film and labels (all certified compostable) are more expensive than the conventional packaging system based on PET-PE based trays. The precise costs were not disclosed. Moreover, the director of the meat company admitted that although the PLA packaging system was more expensive, this was not decisive in the choice for either packaging system. 




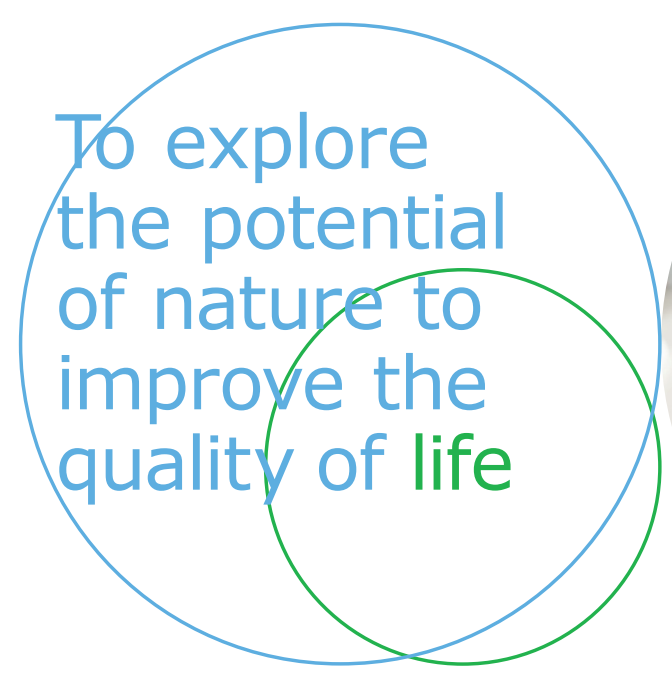

Wageningen Food \& Biobased Research Bornse Weilanden 9

6708 WG Wageningen

The Netherlands

www.wur.eu/wfbr

Einfo.wfbr@wur.nl

Report 2068

ISBN 978-94-6395-467-9

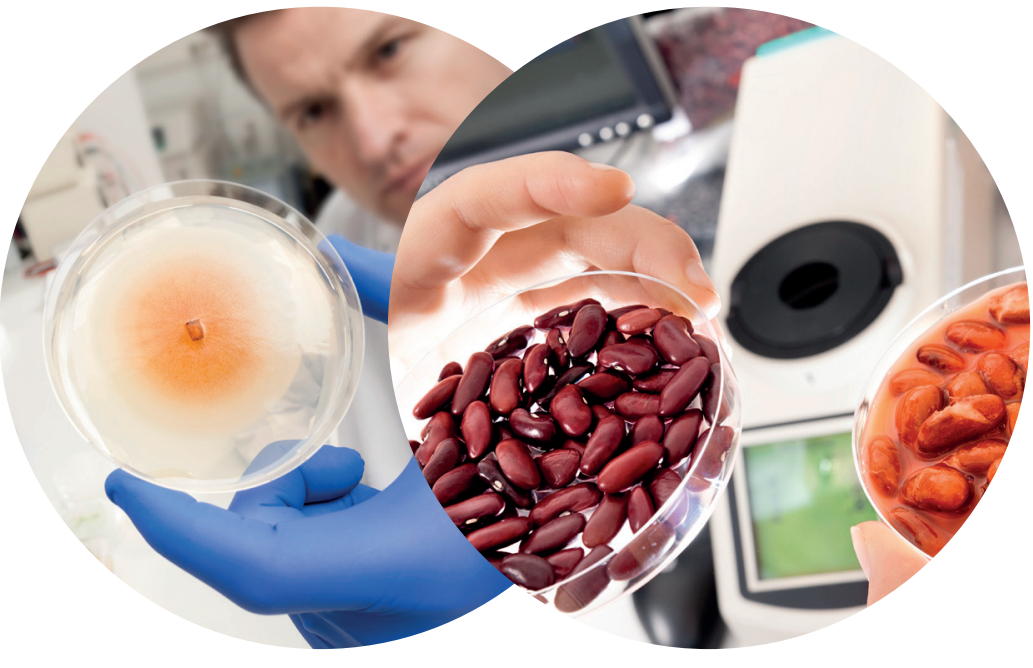

The mission of Wageningen University and Research is "To explore the potential of nature to improve the quality of life". Under the banner Wageningen University \& Research, Wageningen University and the specialised research institutes of the Wageningen Research Foundation have joined forces in contributing to finding solutions to important questions in the domain of healthy food and living environment. With its roughly 30 branches, 5,000 employees and 12,000 students, Wageningen University \& Research is one of the leading organisations in its domain. The unique Wageningen approach lies in its integrated approach to issues and the collaboration between different disciplines. 